\title{
The cell stress response: extreme times call for post- transcriptional measures
}

\author{
Mariavittoria Pizzinga | Robert F. Harvey | Gavin D. Garland | Ryan Mordue | \\ Veronica Dezi | Manasa Ramakrishna | Aristeidis Sfakianos | Mie Monti | \\ Thomas E. Mulroney | Tuija Poyry | Anne E. Willis
}

MRC Toxicology Unit, University of Cambridge, Leicester, UK

\section{Correspondence}

Mariavittoria Pizzinga and Anne E. Willis, MRC Toxicology Unit, University of

Cambridge, Leicester, UK.

Email: mp890@cam.ac.uk (M. P.) and

Email: aew80@cam.ac.uk (A. E. W.)

\section{Funding information}

Medical Research Council, Grant/Award Numbers: MC_UU_0002517 (RG94521), PUAG015; Wellcome Trust, Grant/Award Number: 110071/A/15/Z

\begin{abstract}
Following cell stress, a wide range of molecular pathways are initiated to orchestrate the stress response and enable adaptation to an environmental or intracellular perturbation. The post-transcriptional regulation strategies adopted during the stress response result in a substantial reorganization of gene expression, designed to prepare the cell for either acclimatization or programmed death, depending on the nature and intensity of the stress. Fundamental to the stress response is a rapid repression of global protein synthesis, commonly mediated by phosphorylation of translation initiation factor eIF2 $\alpha$. Recent structural and biochemical information have added unprecedented detail to our understanding of the molecular mechanisms underlying this regulation. During protein synthesis inhibition, the translation of stress-specific mRNAs is nonetheless enhanced, often through the interaction between RNAbinding proteins and specific RNA regulatory elements. Recent studies investigating the unfolded protein response (UPR) provide some important insights into how posttranscriptional events are spatially and temporally fine-tuned in order to elicit the most appropriate response and to coordinate the transition from an early, acute stage into the chronic state of adaptation. Importantly, cancer cells are known to hi-jack adaptive stress response pathways, particularly the UPR, to survive and proliferate in the unfavorable tumor
\end{abstract}

\footnotetext{
Abbreviations: 4E-BPs, 4E-binding proteins; ATF6, activating transcription factor 6; BiP, binding immunoglobulin protein; dsRNA, double-stranded RNA; eEF, eukaryotic elongation factor; eIF, eukaryotic initiation factor; ER, endoplasmic reticulum; GAP, GTPase accelerating protein; GCN2, general control non-derepressible 2; GEF, guanine nucleotide exchange factor; GO, gene ontology; HRI, heme-regulated eIF2 $\alpha$ kinase; IDR, intrinsically disordered region; IRE1, inositol-requiring enzyme 1; IRES, internal ribosome entry site; ISR, integrated stress response; ISRIB, integrated stress response inhibitor; ITAFs, IRES trans-acting factors; LLPS, liquid-liquid phase separation; mTOR, mechanistic target of rapamycin; PERK, PKR-like ER kinase; PIC, pre-initiation complex; PKR, double-stranded RNA (dsRNA)-dependent protein kinase; RBPs, RNA-binding proteins; rHRE, RNA hypoxia-responsive element; RNPs, ribonucleoprotein; ROS, reactive oxygen species; SG, stress granules; tiRNA, stress-induced tRNAs; TISU, translator initiator of short 5' UTR; TOG, terminal oligoguanine; tRNA, transfer RNA; tsncRNAs, tRNA-derived small non-coding RNAs; uORF, upstream open reading frame; UPR, unfolded protein response; UTR, untranslated region.
}

This is an open access article under the terms of the Creative Commons Attribution License, which permits use, distribution and reproduction in any medium, provided the original work is properly cited.

(C) 2019 The Authors. WIREs RNA published by Wiley Periodicals, Inc. 
environment. In this review, we consider the implications of recent research into stress-dependent post-transcriptional regulation and make the case for the exploration of the stress response as a strategy to identify novel targets in the development of cancer therapies.

This article is categorized under: RNA in Disease and Development $>$ RNA in Disease

RNA Evolution and Genomics $>$ RNA and Ribonucleoprotein Evolution

Translation $>$ Translation Mechanisms $>$ Translation Regulation

KE Y W O R D S

eIF2 alpha, mRNA translation, RNA binding proteins, stress response

\section{1 | INTRODUCTION}

Eukaryotic cells rely on the coordination of several complex and evolutionarily conserved molecular mechanisms to maintain homeostasis. Viral infection, exposure to UV light, oxygen deprivation, accumulation of misfolded proteins, and nutrient scarcity are a few among the most common sources of perturbation of physiological homeostasis. When confronted with a perturbating agent, cells initiate stress response pathways. The nature and intensity of the stimulus determine the precise molecular events of the stress response; generally, however, an initial acute phase, characterized by translational repression, prepares the cell for transition into a chronic, adaptive state. In certain circumstances, the adaptive response may fail to overcome the perturbation and programmed cell death will ensue through one of several pathways, including apoptosis and necrosis (Iurlaro \& Muñoz-Pinedo, 2016; Milisav, Poljšak, \& Ribarič, 2017). The cell's ability to adapt to stress is of considerable importance in several pathologies, including neurodegeneration and cancer (Poljšak \& Milisav, 2012).

\section{I POSTTRANSCRIPTIONAL EVENTS GOVERN THE STRESS RESPONSE}

The stress response, in both its acute and chronic stages, is dependent on gene expression regulation processes occurring at various stages in the life cycle of an mRNA. Several post-transcriptional strategies cooperate and affect each other during the response, resulting in an intricate and multi-layered regulatory network (Figure 1).

For instance, the general inhibition of mRNA translation that is common in response to a spectrum of stresses must be coordinated with the enhanced expression of genes that promote cell adaptation to a given perturbation. The selective translation of specific transcripts during translation inhibition is often achieved via the presence of RNA regulatory elements that allow for translation to occur through alternative mechanisms. Moreover, localization of mRNA to translationally inactive cytoplasmic RNP granules, a prevalent and well-studied aspect of the stress response, was found to be intimately connected with other stress-relevant processes such as alternative splicing and miRNA targeting (Kucherenko \& Shcherbata, 2018). Furthermore, across all post-transcriptional strategies, the fate of an mRNA is often regulated with the assistance of RNA-binding proteins (RBPs) (Harvey et al., 2018; Harvey, Dezi, Pizzinga, \& Willis, 2017). Interestingly, recent research highlights the importance of additional post-transcriptional strategies, such as the regulation of tRNA abundance and fragmentation, previously underappreciated in the context of the stress response. Following different stimuli, and even varying intensities of the same stress, multiple pathways combine to deliver distinct overall outcomes. However, certain stresses often arise as a consequence of others, and there is substantial overlap among the responses to different types of perturbations. Central to the stress response is the global arrest and substantial reprogramming of protein synthesis.

\section{1 | Phosphorylation of eIF2: The central tenet of the integrated stress response}

Translation of mRNAs into polypeptides occurs in three stages: initiation, elongation, and termination. Translation represents a rapid mechanism to modulate the proteome and, being estimated to account for $\sim 30 \%$ of the total energy 


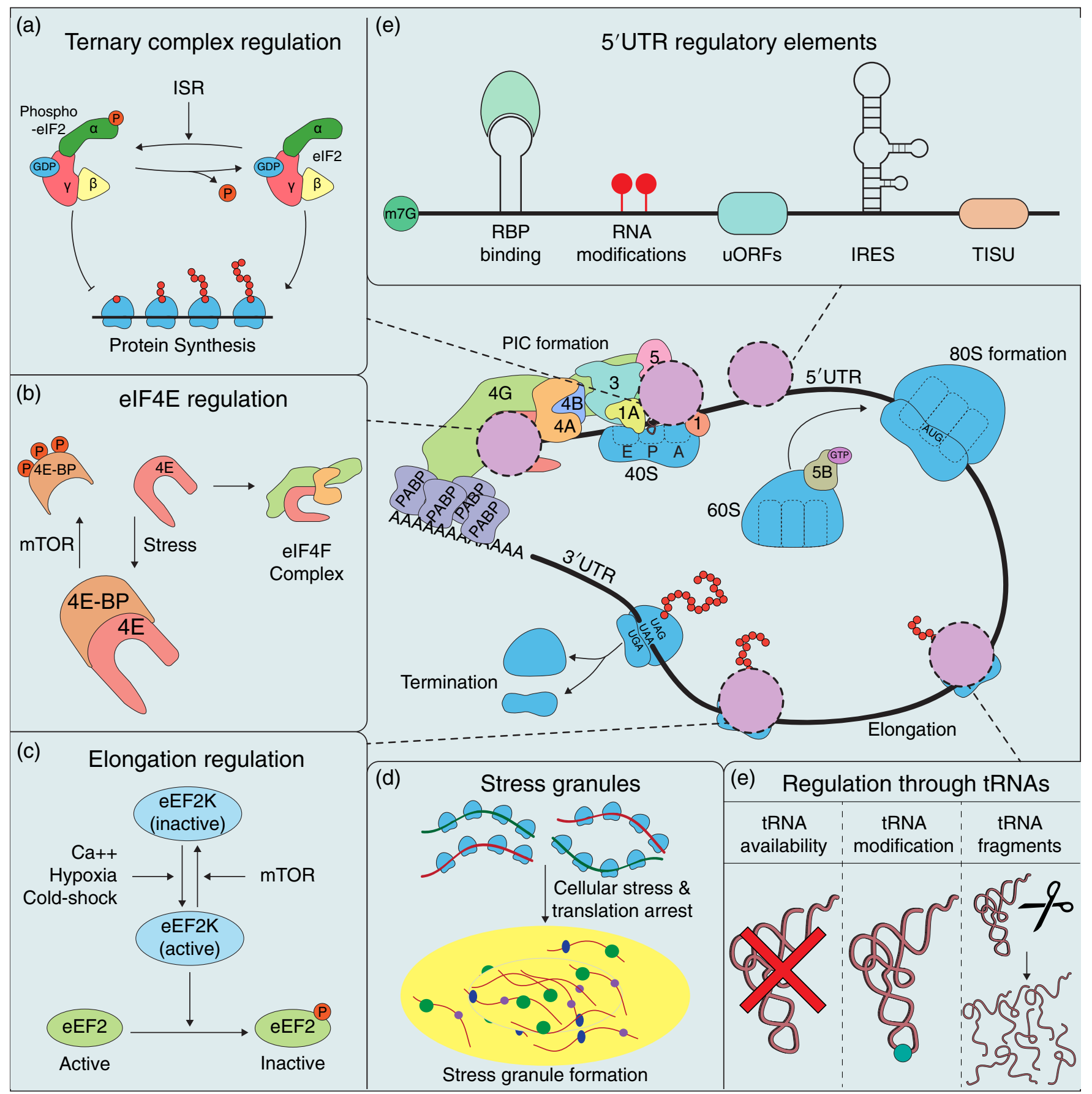

F I G U RE 1 Summary of posttranscriptional regulation strategies during the stress response. (a) Regulation of ternary complex formation through phosphorylation of eIF2 $\alpha$. eIF2 is an heterotrimer consisting of subunits $\alpha, \beta$, and $\gamma$. Subunit $\gamma$ contains the binding sites for GDP/GTP. During the integrated stress response (ISR), phosphorylation of the regulatory subunit $\alpha$ results in impaired formation of the ternary complex and consequent inhibition of protein synthesis. (b) Regulation of eIF4F complex formation through 4E-BPs. In unstressed conditions, 4E-BPs are present in their mTOR-mediated phosphorylated form, unable to bind 4E that can then engage in the formation of the eIF4F complex. During stress, unphosphorylated 4E-BPs sequester eIF4E away from 4F formation, thus impairing translation initiation. (c) Translation elongation is regulated through phosphorylation of eEF2, mediated by eEF2K, which is in turn negatively regulated by mTOR in unstressed conditions and activated upon stress. (d) Formation of stress granule is triggered upon translation inhibition. (e) Several $5^{\prime}$ UTR regulatory elements can affect translation. (f) tRNAs are targets of translation regulation through modulation of their abundance, modification, and fragmentation

consumption in mammalian cells (Buttgereit \& Brand, 1995), its arrest results in significant energy saving. During translation initiation, a crucial step is the formation of an active ternary complex composed by the initiation factor eIF2, a GTP molecule, and a charged initiator methionine tRNA (Met-tRNA $\mathrm{A}_{\mathrm{i}}^{\text {Met }}$ ). In conjunction with eIF3, eIF1, 
eIF1A, and eIF5, the ternary complex binds the 40S ribosomal subunit, thus forming the 43S pre-initiation complex (PIC). For the majority of mammalian transcripts under unstressed conditions, recruitment of the 43S PIC onto the mRNA requires binding of the eIF4F complex-consisting of the cap-binding protein eIF4E, the RNA helicase eIF4A, and the scaffold protein eIF4G - to the m7G cap at the $5^{\prime}$ end. eIF4B and eIF4H also bind to the eIF4F complex to aid the helicase activity of eIF4A. The resulting complex is the 48S PIC and this mode of translation initiation is commonly referred to as cap-dependent initiation. The 48S PIC then scans the mRNA $5^{\prime}$ untranslated region (UTR) for an appropriate start codon based on complementarity with Met-tRNA ${ }_{i}{ }^{\text {Met }}$. During scanning, hydrolysis of eIF2-bound GTP is induced with the assistance of eIF5, which functions as a GTPase accelerating protein (GAP). Upon start codon recognition, joining of the $60 \mathrm{~S}$ ribosomal subunit and release of the initiation factors are catalyzed by eIF5B. In order to later engage with another round of translation initiation, eIF2-GDP is recycled into eIF2-GTP, a process catalyzed by the guanidine exchange factor (GEF) eIF2B (Sonenberg \& Hinnebusch, 2009).

The assembled 80S ribosome, which now presents the Met-tRNA $A_{i}$ paired with the start codon in the P-site and the second codon in the Asite, is then capable of decoding the message in the elongation stage, with the assistance of elongation factors. eEF1 directs the appropriate aminoacyl-tRNA to the A-site while, following peptide bond formation, eEF2 promotes the translocation of the peptidyl-tRNA from the A-site to the P-site. In addition, eIF5A, originally thought to be an initiation factor, acts as an elongation factor by promoting peptide bond formation (Dever \& Green, 2012). Finally, when an in-frame stop codon (UAA, UAG, or UGA) is encountered, the translation machinery embarks on a termination process ending with the release of the polypeptide and recycling of ribosomal subunits (Dever \& Green, 2012).

The initiation factor eIF2 is central to the regulation of translation in response to stress, and phosphorylation of its $\alpha$ subunit is the key event in an elaborate regulatory network known as the integrated stress response (ISR) (Figures 1a and 2). When phosphorylated, eIF2 exhibits increased affinity for its GEF eIF2B, resulting in the "sequestration" of the latter (Pavitt, 2018). This is likely coordinated via the shuttling of eIF2 through cytoplasmic foci to which eIF2B localizes, known as eIF2B bodies (Campbell, Hoyle, \& Ashe, 2005; Hodgson, Varanda, Ashe, Allen, \& Campbell, 2019). As a

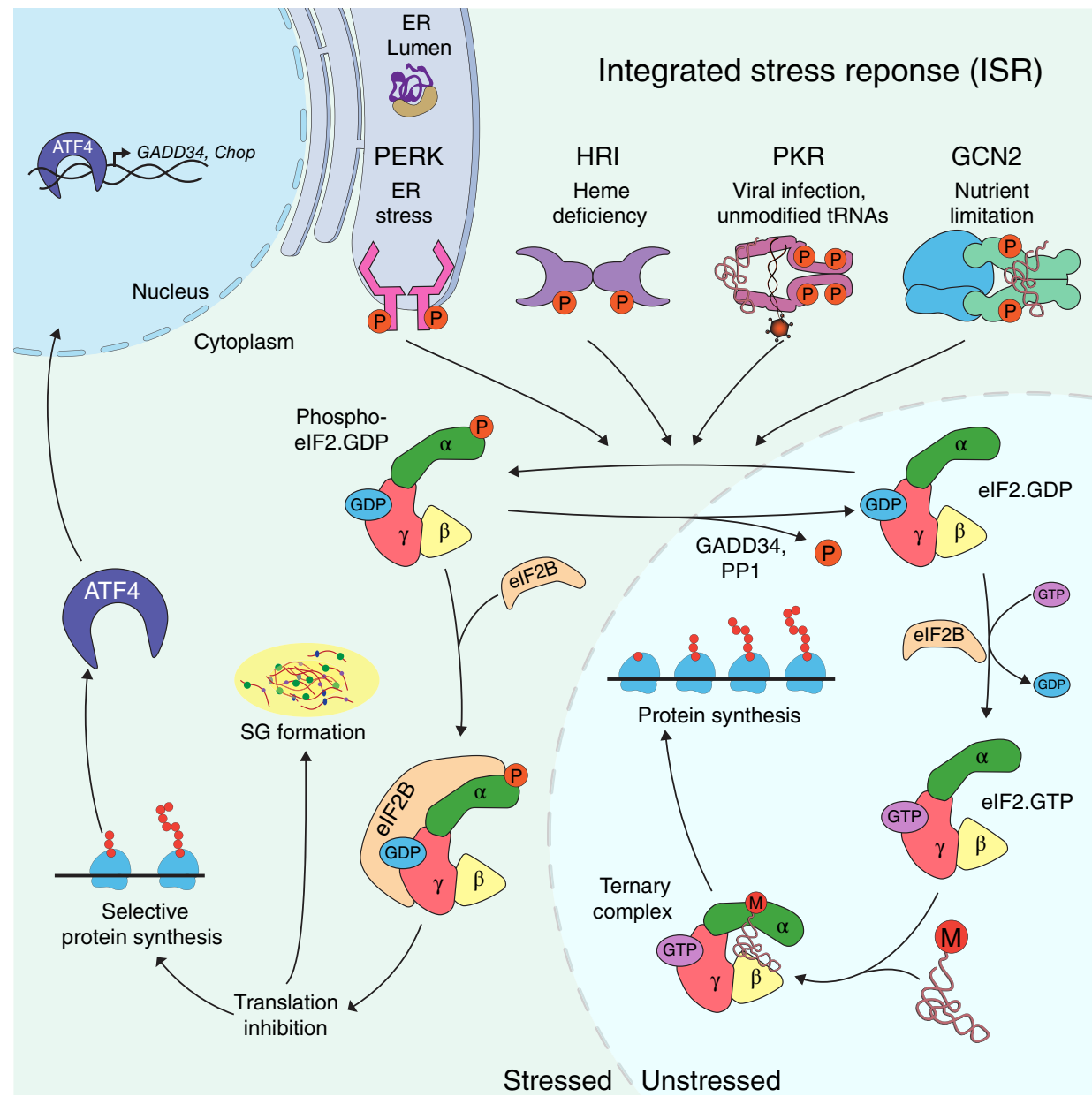

FI G URE 2 Summary of the integrated stress response. Following different stress stimuli, the eIF $2 \alpha$ kinases are activated via autophosphorylation and dimerisation. The kinases subsequently phosphorylate eIF $2 \alpha$, which will sequester eIF2B thus leading to inhibition of protein synthesis, translation of stressspecific transcripts such as transcription factor ATF4, and stress granule formation 
consequence, formation of the ternary complex, and therefore translation initiation, is limited. This regulation is conventionally defined as global since it affects the majority of eukaryotic transcripts. Since the levels of eIF2B are limiting in cells, partial phosphorylation of eIF2 $\alpha$ is sufficient for translational arrest (Pavitt, 2018; Siekierka, Manne, \& Ochoa, 1984). Recent studies have revealed the structural details of the interaction between eIF2 and eIF2B in yeast and in humans (Adomavicius et al., 2019; Gordiyenko, Llácer, \& Ramakrishnan, 2019; Kashiwagi et al., 2019; Kenner et al., 2019). In both organisms, two molecules of eIF2 bind opposite sides of an eIF2B hetero-decamer. In yeast, the complexes formed by eIF2B with either eIF2 or phospho-eIF2 show only minor structural differences; in humans, however, eIF2 binds eIF2B at a different binding site compared to phospho-eIF2 and to both complexes in yeast, with nucleotide exchange occurring on the opposite side of the hetero-decamer (Adomavicius et al., 2019; Gordiyenko et al., 2019; Kashiwagi et al., 2019; Kenner et al., 2019). It has been proposed that this alternative binding site arose in vertebrates to allow for more efficient nucleotide exchange, possibly at the expense of the stability of eIF2B (Gordiyenko et al., 2019). Interestingly, when eIF2 is phosphorylated, eIF2B binds both the GTP- and the GDP-associated forms, suggesting that it might participate in a "failsafe" mechanism aimed at making translation inhibition during stress faster and more secure (Jennings, Kershaw, Adomavicius, \& Pavitt, 2017). After start codon recognition, eIF2-GDP is released in complex with eIF5, which, independently from its GAP activity, also functions as a GDP dissociation inhibitor, providing an additional mechanism to regulate the availability of eIF2 for ternary complex formation (Jennings \& Pavitt, 2010). eIF2B, as well as functioning as a GEF, promotes eIF5 disassociation from eIF2-GDP (Jennings, Zhou, MohammadQureshi, Bennett, \& Pavitt, 2013). Moreover, somehow counterintuitively, eIF2B competes with tRNA $\mathrm{A}_{\mathrm{i}}^{\mathrm{Met}}$ for binding of eIF2, thus reducing the rates of TC formation. Remarkably, however, when the TC is in complex with eIF5, eIF2B is unable to either displace eIF5 or compete with tRNA ${ }_{i}{ }^{\text {Met }}$ binding to eIF2 (Jennings et al., 2017; Pavitt, 2018). eIF5 and eIF2B therefore work in competition to regulate eIF2 recycling, and it has been proposed that varying eIF2B and eIF5 levels or activity in different cell types could be associated with variable sensitivity to the phosphorylation of eIF $2 \alpha$ (Pavitt, 2018; Pavitt \& Ron, 2012), with potential implications for targeting the stress response in therapeutics.

The phosphorylation of eIF2 $\alpha$ occurs at Ser51 and is catalyzed in mammals by four kinases: PKR-like ER kinase (PERK), double-stranded RNA (dsRNA)-dependent protein kinase (PKR), heme-regulated eIF2 $\alpha$ kinase (HRI), and general control non-derepressible 2 (GCN2) (Figure 2). While the catalytic domains of the eIF2 kinases display high homology, allowing them to work in a combinatorial manner and compensate each other in certain circumstances, their regulatory domains are distinct, allowing them to respond to a variety of adverse conditions (Donnelly, Gorman, Gupta, \& Samali, 2013).

PERK, the ER-resident kinase involved in sensing the accumulation of unfolded proteins, will be discussed in further detail in a subsequent section, PERK orchestrates the translational response during different stages of the UPR.

PKR is primarily activated during viral infection, through binding to dsRNAs or other viral RNAs (Bou-Nader, Gordon, Henderson, \& Zhang, 2019). However, PKR may also be regulated by cytoplasmic tRNAs that lack posttranscriptional modifications and by mitochondrial tRNAs (Nallagatla et al., 2013), suggesting that it might function as a sensor of mitochondrial integrity (Bou-Nader et al., 2019; Kim et al., 2018). Moreover, PKR has been shown to regulate the response to DNA damage (Bergeron et al., 2000; Peidis, Papadakis, Muaddi, Richard, \& Koromilas, 2011) and ER stress (Nakamura et al., 2010).

HRI is responsible for sensing the scarcity of heme during erythropoiesis (J.-J. Chen, 2014) and regulates the response to oxidative stress in blood cells (Suragani et al., 2012). However, HRI is also functional in non-blood cells, where it's been implicated in the response to arsenite (McEwen et al., 2005), although the extent and details of this involvement remain unclear.

The most ancient of the eIF2 $\alpha$ kinases, GCN2, is responsible for sensing amino acid shortage (Hinnebusch, 1984). It was originally proposed that the main mechanism by which GCN2 could sense amino acid starvation was by binding to deacylated (uncharged) tRNAs. This hypothesis is consistent with the observation that GCN2 possesses a His-tRNA synthetase-like domain that interacts with several uncharged tRNAs and that is essential for activation of the kinase (Wek, Zhu, \& Wek, 1995). A system based on the binding of GCN2 to deacylated tRNAs would be in line with the bacterial stringent response, in which uncharged tRNA binds to the acceptor site in the ribosome and recruits RelA, which in turn synthesizes the alarmone nucleotide (p)ppGpp (Zhu, Pan, \& Dai, 2019). However, recent work has shown that phosphorylation of eIF $2 \alpha$ by GCN2 in vitro is increased by $\sim 20$-fold in the presence of ribosomes compared to deacetylated tRNAs (Inglis et al., 2019). Accordingly, GCN2 was found to interact with the ribosomal complex P-stalk and to be activated by stalling ribosomes (Darnell, Subramaniam, \& O'Shea, 2018; Inglis et al., 2019). Although the precise mechanism by which this activation is restricted to stress conditions in vivo is still unclear, these observations suggest a mechanistic link between the control of translation elongation and the control of translation initiation. 


\section{2 | Additional translation regulatory mechanisms are targeted in the stress response}

In addition to eIF $2 \alpha$ phosphorylation, stress influences translation through several other pathways, among which we can highlight a few notable examples. The Ser/Thr protein kinase mechanistic target of rapamycin (mTOR), which in mammalian cells is found in two distinct complexes, mTORC1 and mTORC2, integrates a diverse array of extracellular and intracellular regulatory signals, with potentially hundreds of proteins influencing its activity. In its active form, which is promoted by positive signals such as nutrients and growth factors, mTORC1 enhances protein synthesis through phosphorylation of the S6 kinases 1 and 2 (S6K1, S6K2) and of eIF4E-binding proteins (4E-BPs)(Saxton \& Sabatini, 2017). S6K1 and S6K2, in their phosphorylated and active form, phosphorylate several targets, positively affecting translation in a variety of manners. For example, phosphorylation of eIF4B results in increased translation initiation (Holz, Ballif, Gygi, \& Blenis, 2005; Shahbazian et al., 2006), while PDCD4, a suppressor of eIF4A activity, is targeted for degradation upon phosphorylation (Dorrello et al., 2006). The 40S ribosomal protein S6 (rpS6) is also phosphorylated by S6K1 and S6K2, although it would appear that this event results in a reduction of protein synthesis, possibly as a way to counterbalance the stimulatory effects of other S6K targets (Ruvinsky \& Meyuhas, 2006).

On the other hand, upon phosphorylation by mTOR, 4E-BPs become unable to bind eIF4E, which can therefore participate in translation initiation as part of the eIF4F complex (Figure 1b). Scarcity of amino acids or glucose, as well as other hostile conditions such as low oxygen, low energy, high ROS levels, and DNA damage, result in the inactivation of mTOR, with a consequent reduction in the level of phosphorylation of its target proteins (Saxton \& Sabatini, 2017). In their stress-induced dephosphorylated status, 4E-BPs sequester eIF4E, thus inhibiting cap-dependent translation. However, up to $20 \%$ of capped mRNAs can be translated in a cap-dependent yet eIF4E-independent manner via DAP5, an eIF4G homolog that does not bind to eIF4E but instead interacts with eIF3d to mediate initiation (de la Parra et al., 2018). It seems plausible that this alternative model of cap-dependent translation might be important in the stress response, especially in light of recent reports about the prominence of eIF3-dependent translation in the adaptation to ER stress (Guan et al., 2017).

Translation elongation is also a critical target for regulation during the stress response (Figure 1c). The elongation factor eEF2 can be phosphorylated by its kinase eEF2K; this phosphorylation interferes with eEF2 binding to the ribosome and elongation rates are slowed as a result (Carlberg, Nilsson, \& Nygard, 1990; Proud, 2015). Cold shock and oxidative stress, as well as high levels of $\mathrm{Ca}^{2+}$, trigger the activation of eEF2K, which is in contrast regulated negatively by mTOR (Dever \& Green, 2012; Knight et al., 2015; Proud, 2015), and the activity of eEF2 can also be modulated through the binding of RBPs (R. Harvey et al., 2017).

In addition to targeting translation factors, protein synthesis can be regulated through the formation of cytoplasmic membrane-less foci known as stress granules (SGs) (Figure 1d), which contain translationally inactive mRNAs and various RBPs. The RBPs found in SGs often contain intrinsically disordered regions (IDRs) that promote SG formation through a phenomenon termed liquid-liquid phase separation (LLPS) (Molliex et al., 2015; Niewidok et al., 2018; Riback et al., 2017; Sfakianos, Whitmarsh, \& Ashe, 2016). Recent studies have described SGs as liquid droplets consisting of a solid core, harboring proteins and mRNAs, and an aqueous shell, the content of which is unclear (Jain et al., 2016; Niewidok et al., 2018). Although the precise function of SGs is still uncertain, they have long been considered sites of mRNA storage since they appear to contain mRNAs in a translationally repressed state. However, it has been proposed that the outer shell might increase the efficiency of enzymatic reactions via molecular crowding, possibly enhancing stress-related reactions (Sfakianos et al., 2016). Although some core components of SGs have been identified, for example, G3BP1 and TIA-1, the combination of proteins present in SGs is highly dependent on the stress stimulus (Aulas et al., 2017; Harvey et al., 2017). For example, S6K1 and S6K2 localize to SGs and regulate their formation during mild, but not acute oxidative stress (Sfakianos et al., 2018). Conversely, there does not appear to be a specific requirement for mRNA entry into the granules and the mRNA composition mostly does not differ depending on the stress (Khong et al., 2017). However, a recent study identified a notable exception in SGs that form following treatment with eIF4A1-inhibitor hippuristanol, which appear to contain a different subset of mRNAs compared to heat shock- or arsenite-induced SGs (Padrón, Iwasaki, \& Ingolia, 2019). A possible explanation for this difference could be that mRNAs are recruited to SGs depending on their interaction with eIF4A1, which is disrupted by hippuristanol. Alternatively, the difference might be due to hippuristanol-triggered SGs being independent of eIF2 $\alpha$ phosphorylation, in contrast with SG formation triggered by most other stresses. Moreover, SGs are enriched for longer mRNAs and mRNAs that are less efficiently translated; while transcripts associated with ER and mitochondrial membranes were less likely to localize to SGs (Khong et al., 2017). Importantly, recent studies suggest that stress-induced methylation $\left(\mathrm{m}^{6} \mathrm{~A}\right)$ in the $5^{\prime}$ UTR and 5' terminal coding region of mRNAs can promote LLPS (Anders et al., 2018; Ries et al., 2019), but repel 
some RBPs such as G3BP1 (Edupuganti et al., 2017). It has therefore been proposed that, while IDR-containing RBPs promote the nucleation of the solid core, LLPS of the outer phase might involve dynamic mRNA modifications (Anders et al., 2018).

\subsection{Escaping translation repression: The role of RNA elements in the expression of stress-specific genes}

As described above, the stress-induced repression of protein synthesis is often considered global, as it involves the majority of transcripts. However, crucially, translation of a subset of stress-specific mRNAs is maintained or enhanced, very often by exploiting the presence of specific cis-acting elements within their $5^{\prime}$ UTRs (Figure 1e) (Leppek, Das, \& Barna, 2018).

For example, upon phosphorylation of eIF2 $\alpha$, the translation of certain transcripts containing upstream open reading frames (uORF) within their $5^{\prime}$ UTR is increased. Two of the best defined examples are the mammalian transcription factor ATF4 and its yeast homolog GCN4, which promote the transcription of important stress-related genes such as the apoptosis-mediator CHOP (Fawcett, Martindale, Guyton, Hai, \& Holbrook, 1999; Harding et al., 2000) and the eIF2 $\alpha$ phosphatase GADD34 (Ma \& Hendershot, 2003). Upstream of its coding regions, ATF4 contains two uORFs, with the second uORF overlapping with the start of the protein-coding sequence, and the first uORF functioning as a positive-acting element that promotes ribosome scanning and re-initiation at downstream sites. In absence of stress, when eIF2 $\alpha$ is not phosphorylated and the ternary complex forms rapidly, the overlapping uORF is translated and the protein-coding region is bypassed, thus the ATF4 protein is not synthesized. Under stress conditions, due to the slower turnover of ternary complex, the 40S subunit will scan through the overlapping uORF and reinitiate translation at the start codon of the ATF4 coding sequence (Harding, Novoa, et al., 2000; Lu, Harding, \& Ron, 2004; Vattem \& Wek, 2004).

Start-codon recognition is aided by eIF1 which mediates disassociation of the $43 \mathrm{~S}$ complex from non-AUG codons, AUG codons in non-favorable contexts, and AUG codons too close to the $5^{\prime}$ end (Pestova \& Kolupaeva, 2002). mRNAs with very short $5^{\prime}$ UTRs are therefore normally excluded from translation. However, the TISU (translator initiator of short $5^{\prime}$ UTR) element, normally positioned very close to the m7G cap and present in several transcripts associated with mitochondrial activity and energy metabolism, allows for cap-dependent but scanning-free translation initiation of transcripts with short 5' UTR (Elfakess \& Dikstein, 2008). Although the molecular details of this process are not completely understood, it is possible that the TISU element makes the AUG context more favorable for the formation of the $48 \mathrm{~S}$ and the subsequent joining of the $60 \mathrm{~S}$ subunit, possibly by binding ribosomal proteins RPS3 and RPS10e and with the assistance of eIF1A (Haimov et al., 2017). In response to energy deprivation, TISU-containing transcripts bypass eIF4E inhibition and continue to be translated, enabling cells to cope with the stress (Sinvani et al., 2015).

Another class of $5^{\prime}$ UTR elements, known as internal ribosome entry site (IRES), allow for cap-independent initiation. Since their initial discovery in viral RNAs (Jang, Pestova, Hellen, Witherell, \& Wimmer, 1990; Pelletier \& Sonenberg, 1988) more than 100 IRES elements have been described in eukaryotic mRNAs, very often within transcripts implicated in the stress response (Hellen \& Sarnow, 2001; Qin \& Sarnow, 2004; Spriggs, Bushell, Mitchell, \& Willis, 2005). IRES-containing transcripts are regulated through a variety of mechanisms, often via RBPs acting as IRES trans-acting factors, or ITAFs (Godet et al., 2019; Spriggs, Bushell, \& Willis, 2010). For example, PTB was found to be required for the function of many viral and mammalian IRESs (Mitchell et al., 2005).

Moreover, in conditions of oxygen deprivation-commonly known as hypoxia-cells can partially circumvent eIF4E inhibition through a complex formed by hypoxia-inducible factor $2 \alpha$ (HIF2 $\alpha$ ), the RNA-binding protein RBM4, and eIF4E2, an eIF4E homolog with lower affinity for 4E-BPs (Uniacke et al., 2012). This complex selectively promotes translation of mRNAs containing an RNA hypoxia-responsive element (rHRE). After binding to the rHRE, the HIF2 $\alpha-$ 4E2-RBM4 complex engages the $5^{\prime}$ cap and recruits eIF4A, thus priming the mRNA for active translation. Among the mRNA targets of this alternative mode of translation are transcripts encoding proteins that have been implicated in the adaptive response to hypoxia (Uniacke et al., 2012). This example further illustrates how specific transcripts can be subjected to differential control through the combinatorial binding of trans-acting regulatory factors, including RBPs. Interestingly, RNA modifications have also been found to affect translation following stress. For example, heat shock and UV irradiation enhance $\mathrm{m}^{6} \mathrm{~A}$ modifications in the $5^{\prime}$ UTR of transcripts, which can trigger eIF3-mediated capindependent translation (Meyer et al., 2015). 
Remarkably, mRNAs are not the only RNA species that play an active role in the stress response. For example, ribosomes containing $2^{\prime} \mathrm{O}$-methylated rRNA were found to be involved in the translation of several IRES-bearing transcripts (Erales et al., 2017; Marcel, Catez, \& Diaz, 2015).

Moreover, tRNAs are also regulated in a variety of manners during the stress response.

\section{3 | STRESS-INDUCED REGULATION OF TRNA AND TRNA FRAGMENTS}

\section{1 | tRNA abundance and modifications}

The rate of protein synthesis can be altered by coordinating the availability of cognate aminoacyl tRNAs for elongating ribosomes with the specific codon usage of an mRNA (Gingold \& Pilpel, 2011). tRNA abundance can be regulated at the level of transcription, pre-tRNA processing and maturation, or aminoacylation, and mature tRNAs may also accumulate in the nucleus in response to stress (Huang \& Hopper, 2016). Recent research has focused on how the "economy" of tRNA availability and mRNA codon usage is regulated in response to stress or other stimuli. In response to oxidative stress, hyperosmotic stress, and heat shock, the abundance of subsets of tRNAs has been shown to change in yeast, possibly in order to increase the relative translation efficiency of specific transcripts encoding proteins required for adaptation to stress (Torrent, Chalancon, de Groot, Wuster, \& Madan Babu, 2018). tRNAs can also undergo retrograde transport to the nucleus, both in normal conditions, as part of their maturation or quality control, and during nutrient deprivation (Dhakal et al., 2019; Kramer \& Hopper, 2013; Ohira \& Suzuki, 2011; Shaheen \& Hopper, 2005). Following oxidative stress, nuclear accumulation seems to be tRNA-specific (Schwenzer et al., 2019), raising the possibility that the translation of codon-biased mRNAs can be regulated by changes in the subcellular distribution of tRNA.

The structural and functional status of tRNA molecules is regulated through extensive posttranscriptional modifications, mediated by epitranscriptomic writer enzymes (de Crécy-Lagard et al., 2019; Schimmel, 2018). The tRNA anticodon loops are a particular hotspot for modifications, predominantly at position 34, the "wobble" base (Boccaletto et al., 2018), where they allow for decoding of synonymous codons and restrict pairing with noncognate codons (Agris, Vendeix, \& Graham, 2007). Remarkably, in yeast cells exposed to oxidative stress, an increase in methylation of the cytosine in position 34 of tRNA ${ }^{\mathrm{Leu}(\mathrm{CAA})}$ molecules results in selective translation of stress-response transcripts containing a TTG codon (Chan et al., 2012). Treatment with different alkylating agents also results in specific tRNA modification patterns (Chan et al., 2015). In mammals, a specialized tRNA ${ }^{\mathrm{Sec}}$ containing a 5-methoxycarbonylmethyluridine $\left(\mathrm{mcm}^{5} \mathrm{U}\right)$ at the wobble base decodes the rare amino acid selenocysteine, which is enriched in proteins involved in the response to ROS. The $\mathrm{mcm}^{5} \mathrm{U}$ modification is mediated by the methyltransferase ALKBH8, which has been found to be necessary for the response to ROS as well as for the growth of certain tumors (Begley et al., 2013; Endres et al., 2015).

\section{2 | tRNA fragments}

Fragments generated from pre-tRNAs and mature tRNAs, collectively known as tRNA-derived small non-coding RNAs (tsncRNAs), have also been implicated in the response to cell stress, as well as in several other biological processes (Fu et al., 2009; Kawaji et al., 2008; Thompson, Lu, Green, \& Parker, 2008). Among the sub-groups of tsncRNAs, which have been extensively reviewed elsewhere (Shen et al., 2018), it is the role of tRNA-derived stress-induced halves (tiRNAs) that is most relevant and well-studied with respect to the stress response (Fu et al., 2009). In mammals, the secreted ribonuclease angiogenin (ANG) mediates cleavage of mature tRNAs within the anticodon loops to produce tiRNAs as either $5^{\prime}$ or $3^{\prime}$ halves (Fu et al., 2009). In response to stress, ANG is transcriptionally upregulated (Kishimoto et al., 2012; Pereira, Liao, Neale, \& Hendershot, 2010), leading to the accumulation of tiRNAs (Thompson et al., 2008; Yamasaki, Ivanov, $\mathrm{Hu}, \&$ Anderson, 2009). This induces the formation of stress granules and reduces global protein synthesis in a phospho-eIF2 $\alpha$-independent manner (Emara et al., 2010; Yamasaki et al., 2009). Specifically, $5^{\prime}$ tiRNA ${ }^{\text {Ala }}$ and $5^{\prime}$ tiRNA $^{\text {Cys }}$ displace the eIF4F complex, thus preventing cap-dependent translation initiation (Ivanov, Emara, Villen, Gygi, \& Anderson, 2011). Both stress granule formation and translational repression activities are dependent on the presence of a $5^{\prime}$ terminal oligoguanine ( $5^{\prime}$ TOG) motif on the tiRNAs (Lyons, Achorn, Kedersha, Anderson, \& Ivanov, 2016). Since $5^{\prime}$ TOG-containing tiRNAs do not affect cap-independent translation, it has been hypothesized that IRES-containing mRNAs might be exempted from this tiRNA-mediated repression, which would thereby redirect protein synthesis toward stress survival strategies (Lyons, Fay, Akiyama, Anderson, \& Ivanov, 2017). The translational 
silencer protein YBX1 (YB-1) associates with tiRNAs and was initially thought to assist in the inhibition of translation initiation (Ivanov et al., 2011). However, more recent studies have detailed the role of YBX1 as being fundamental for tiRNA-induced stress granule formation, but not for translational repression (Lyons et al., 2016). Interestingly, YBX1 might also be acting as a tumor suppressor upon interaction, in a sequence-specific manner, with a class of tsncRNAs that contain CU-box motifs and competitively displace endogenous oncogenic transcripts from YBX1 resulting in their destabilization and consequent post-transcriptional suppression (Goodarzi et al., 2015).

In addition to being crucial for the correct functioning of tRNAs in several ways, some post-transcriptional tRNA modifications also affect ANG-mediated tRNA cleavage in response to stress. For example, in various tRNAs methylation of cytosine carbon $-5\left(\mathrm{~m}^{5} \mathrm{C}\right)$ is catalyzed at position 38 by DNMT2 and at positions 48 and 49 by NSUN2. These modifications protect against stress-induced ANG-mediated tRNA cleavage (Blanco et al., 2014; Goll et al., 2006; Schaefer et al., 2010) and deletion of DNMT2 or NSUN2 results in accumulation of tiRNAs and increased sensitivity to thermal and oxidative stress (Blanco et al., 2014; Schaefer et al., 2010). Furthermore, NSUN2 and other $\mathrm{m}^{5} \mathrm{C}$ RNA methyltransferase family members are repressed in response to oxidative stress, leading to site specific loss of $\mathrm{m}^{5} \mathrm{C}$ in tRNAs which in turn affects the biogenesis of tRNA fragments. In particular, there is an increase in tRNA fragments derived from tRNA ${ }^{\mathrm{Glu}(\mathrm{CTC})}$, which reportedly act to repress protein synthesis and adapt cell cycle progression to the early stress response (Gkatza et al., 2019). Although as yet unproven, it is probable that post-transcriptional tRNA modifications also modulate the functionality of tsncRNAs and it would be informative for future studies to address this possibility (Goodarzi et al., 2015). In some of these studies, it may be that the levels of transfected tiRNAs exceed physiological levels, which would have artifactual effects on translation. Only a minor fraction $(<5 \%)$ of the tRNA pool is cleaved (Anderson \& Ivanov, 2014), with the abundance of specific $5^{\prime}$ tiRNA species being comparable to the most prevalent miRNAs (Cole et al., 2009); however, the transfection efficiency of tiRNAs can be variable. Future research will hopefully shed a light on the biological significance of tiRNAs and other tsncRNAs in the stress response.

In conclusion, a role for tRNA abundance, modification, and fragmentation in regulation is starting to be delineated (Figure 1f). However, to understand the broader relevance of tRNAs and tsncRNAs in the context of response and adaptation to cellular stress, several questions remain to be addressed. For example, although correlations between translation efficiency and tRNA abundance have been identified, little is currently known about the underlying regulatory mechanisms. To address this question, it would be necessary to be able to discern the portion of charged from uncharged tRNA. The spatiotemporal organization of tRNAs in response to stress is also a promising area to investigate. Moreover, it remains to be fully understood why only specific subsets of these tiRNAs are functional and how these specific tiRNAs mechanistically reprogram cellular translation (Lyons et al., 2017). The scope of future research in the field will obviously rely on the development of new and improved research tools. At present, multiple different methods have been published that allow for the quantification of tRNAs via high-throughput sequencing (Cozen et al., 2015; Gogakos et al., 2017; Pang, Abo, Levine, \& Dedon, 2014; Shigematsu et al., 2017; Zheng et al., 2015), but a direct comparison among them is not yet available and there is currently no consensus about a gold standard in the field. Analysis of tRNA sequencing data also presents some challenges: for example, different alignment approaches can yield different estimates of tRNA abundance from the same reads (Wu, Yao, Ho, Lambowitz, \& Wilke, 2018). Moreover, current alignment methods do not account for errors in cDNA due to tRNA modifications at defined positions. However, developments in mass spectrometry-based RNA sequencing (Oberacher, Mayr, \& Huber, 2004) and nanopore sequencing may provide complementary or alternative methods to quantify and characterize tRNA which do not rely on cDNA (Smith, Abu-Shumays, Akeson, \& Bernick, 2015).

\section{4 | TRANSITIONING FROM ACUTE TO CHRONIC RESPONSE DURING ER STRESS}

As the first compartment involved in the secretory pathway, the endoplasmic reticulum (ER) is the site at which translation, folding, and initial sorting occur for proteins destined for other organelles or the extracellular space. This spatial restriction creates a bottleneck in the protein production pipeline and, in certain circumstances, the protein folding load in the ER exceeds its protein folding capacity, resulting in an accumulation of unfolded or misfolded proteins. This situation is commonly referred to as ER stress and it activates the unfolded protein response (UPR). Overexpression or mutations in secreted proteins, as well as disturbances in calcium homeostasis, are common causes of ER stress; however, other types of stress also often result in ER accumulation of unfolded proteins. For example, during hypoxia, 


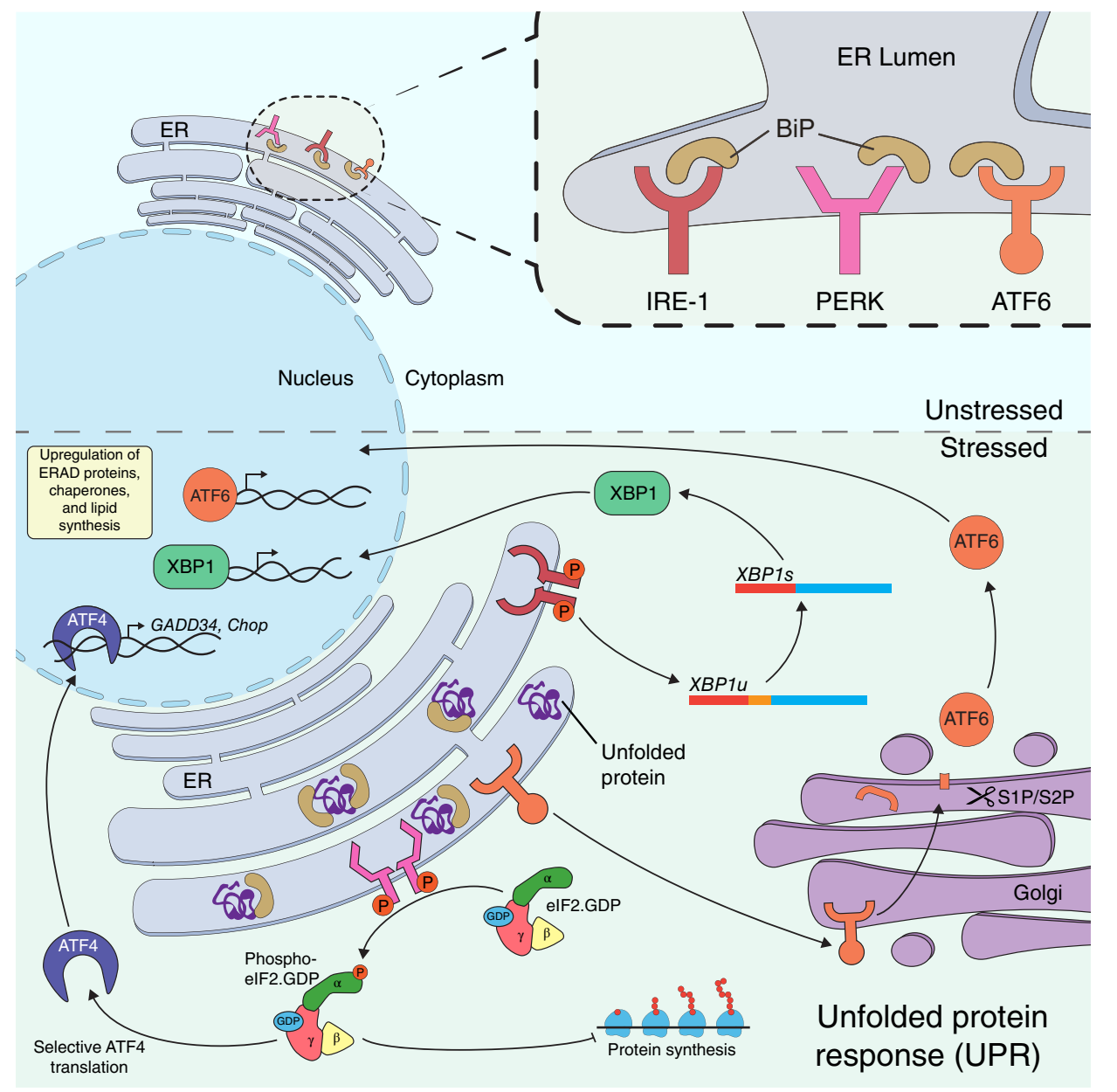

F I G URE 3 Summary of the unfolded protein response. During ER stress, the three branches of the UPR (ATF6, IRE1, and PERK) are activated through ER chaperone BiP. PERK phosphorylates eIF $2 \alpha$, causing translation inhibition and translation of stress-specific transcripts. IRE1 splices XBP1 mRNA to obtain functional transcription factor XBP1. ATF6 is relocated to the Golgi, where it is cleaved. XBP1 and cleaved ATF6 relocate to the nucleus to enhance the expression of stress-specific genes. UPR, unfolded protein response

oxygen-dependent protein-folding processes are impaired, while perturbations in the redox state of the ER interfere with disulfide bond formation (Grootjans, Kaser, Kaufman, \& Blumberg, 2016). Excessive protein folding in the ER can also lead to the formation of ROS, strongly linking the UPR with oxidative stress (Zeeshan, Lee, Kim, \& Chae, 2016).

The UPR is activated in the ER via three evolutionary distinct branches, each dependent on one of three stress sensors embedded in the ER membrane: inositol-requiring enzyme 1 (IRE1), protein kinase R (PKR)-like endoplasmic reticulum kinase (PERK), and activating transcription factor 6 (ATF6) (Figure 3). In all cases, central to stress sensing is the ER-resident chaperone BiP, also known as GRP78.

In order to reestablish the correct protein folding homeostasis, the UPR initiates mechanisms aimed at either reducing the protein folding load, for example by halting translation and degrading proteins and RNA, or increasing the protein folding capacity, through the upregulation of ER chaperones (Díaz-Villanueva, Díaz-Molina, \& García-González, 2015). However, an unresolved but important question concerns how the response pathways are coordinated over time.

\section{1 | PERK orchestrates the translational response during different stages of the UPR}

In its early, acute phase, the UPR is characterized by a substantial repression of translation mediated by PERK-induced phosphorylation of eIF2 $\alpha$ (Harding, Zhang, Bertolotti, Zeng, \& Ron, 2000). Interestingly, if PERK is inhibited over longer treatments, the levels of phospho-eIF $2 \alpha$ decrease initially but are restored within $2 \mathrm{hr}$, hinting at a safety mechanism that allows for other eIF2 $\alpha$ kinases to substitute PERK during the chronic UPR (Guan et al., 2017). Translational repression is then slowly relieved over longer treatments, as the cell gradually adapts to the stressful condition during a phase that is generally thought of as the chronic UPR (Novoa et al., 2003). This adaptation is partly the result of the upregulated expression of eIF2 $\alpha$ phosphatase GADD34 (Ma \& Hendershot, 2003; Novoa et al., 2003). However, throughout this recovery the levels of phospho-eIF2 $\alpha$ are reduced, but not depleted, suggesting that phosphorylation 
alone might not be sufficient to maintain the chronic UPR (Guan et al., 2017). Importantly, the chronic UPR is reversible and does not necessarily commit cells to apoptosis, with cells being able to fully recover protein synthesis and restore proliferation upon removal of the stress (Guan et al., 2017).

Several studies have integrated various high-throughput technologies-such as RNA sequencing, proteomics, ribosome footprinting, and protein occupancy profiling - to investigate transcriptional and post-transcriptional regulation strategies across different stages of the UPR (Gonen, Sabath, Burge, \& Shalgi, 2019; Guan et al., 2017; Reid, Chen, Tay, Shenolikar, \& Nicchitta, 2014; Rendleman et al., 2018). The remarkable concordance across these studies allows us to identify some important trends, from which some intriguing hypotheses emerge.

Although translation is globally reduced as part of the stress response, transcripts that encode ER targets-such as transmembrane proteins, glycoproteins, and disulfide bond-containing proteins-are predominantly affected, and their translation remains repressed even after the global translational arrest is relaxed (Guan et al., 2017; Reid et al., 2014; Rendleman et al., 2018). Spatial reorganization also appears to be crucial in the regulation of ER-target mRNAs, as they were found to be released into the cytosol from the ER, together with a portion of their associated ribosomes, after only 30 min of ER stress (Reid et al., 2014). Surprisingly, while several of these transcripts are translationally stalled following ER release, some are still partially translated in the cytosol, suggesting that the primary aim of this phenomenon is to prevent these proteins from entering the ER rather than from being synthesized. Remarkably, the UPR-triggered release seems to exempt a certain class of ER-associated transcripts, specifically those that encode proteins involved in the degradation and removal of proteins from the ER (Reid et al., 2014). It is interesting that this exemption does not extend to mRNAs encoding ER chaperones, suggesting that load-reducing strategies are likely to be given priority temporally over strategies that increase protein-folding capacity (Reid et al., 2014). The mechanism by which this phenomenon is regulated is currently not characterized, but it is likely to involve a finely tuned coordination of the interactions between the ER, the ribosome, the nascent chain, and the RNA itself, as well as the modulation of the activity of RNAbinding proteins.

PERK-dependent general translation repression during the early UPR is accompanied by an increase in the translation of ATF4 and hundreds of additional transcripts that, unsurprisingly, show an enrichment for the presence of $5^{\prime}$ UTR uORFs (Guan et al., 2017; Rendleman et al., 2018). However, several of the translationally upregulated mRNAs do not contain uORFs, indicating that different mechanisms might influence transcript-specific translation regulation during the UPR. In fact, TISU elements are found in the $5^{\prime}$ UTR of several transcripts encoding mitochondria-localized proteins, which are also significantly enriched among the upregulated mRNAs. These mitochondrial proteins are predominantly involved in one-carbon metabolism, implying an association between ER stress and a shift in energy metabolism. Moreover, an increase in translation was found to be accompanied by increased protein occupancy in the 3' UTR of the transcripts, suggesting a partly unexplored role for RNA-binding proteins in the UPR (Rendleman et al., 2018).

A significant increase in translation was also observed across different studies for transcripts encoding histones and other DNA-binding proteins, suggesting that ER stress-related chromatin rearrangements may occur (Gonen et al., 2019; Guan et al., 2017; Reid et al., 2014).

While the early UPR induction programme relies almost solely on an increase in translation of select mRNAs, in the late UPR a considerable number of genes specific to the ER stress response, as well as genes involved in the biosynthesis of amino acids, are upregulated coordinately at the transcriptional and translational levels (Gonen et al., 2019; Guan et al., 2017; Novoa et al., 2003; Reid et al., 2014; Rendleman et al., 2018). A small number of targets are only translationally upregulated during the chronic UPR (Guan et al., 2017; Rendleman et al., 2018). Surprisingly, however, transcriptional and post-transcriptional regulation was found to be in discordance for several genes. For example, the transcription of DNA repair genes is enhanced early in the response, whereas the translation of the corresponding transcripts is paused. This phenomenon might be common across the response to different stresses, as the same pattern was observed in cells subjected to oxidative stress (Rendleman et al., 2018). This has been proposed to be a case of "transcriptional priming," where cells induce bulk transcription of certain genes so that their translation can later be fine-tuned depending on the outcome of the stress response, thus providing a certain degree of maneuverability in the determination of cell fate (Rendleman et al., 2018).

Therefore, the later stages of the stress response are not a simple amplification of the early UPR, nor should the adaptive recovery of translation be considered merely a reversal of the initial inhibition. Rather, the chronic UPR seems to encompass a profound reprogramming of the translational apparatus, with recent insights painting a surprising, although possibly still incomplete, picture. For example, during the chronic UPR, the requirement for eIF2B appears to be bypassed; it has been reported that depletion of the catalytic subunit of eIF2B, eIF2Be, impairs the early preferential 
translation of stress-responsive transcripts, but does not affect the later recovery of protein synthesis nor the translation of the same genes (Guan et al., 2017). Moreover, evidence from the same study suggests that, during the chronic UPR, translation initiation also seems to be at least partially independent of eIF4F. In fact, the recovery of translation is affected only moderately by eIF4E depletion, inhibition of eIF4F assembly, or inhibition of eIF4A activity, which all significantly impair translation initiation in unstressed cells. In addition, the association of eIF3 with mRNA and with the ribosome is increased during ER stress, and depletion of certain eIF3 subunits differentially affects the translation of specific stress-responsive transcripts. When co-treating the cells with a PERK inhibitor for the final part of an ER stressinducing treatment, these effects are reversed. Therefore, a model was proposed in which, during the chronic UPR, translation initiation is switched, via activation of the PERK pathway, to a system where the critical role in the recruitment of the mRNA to the 40S subunit is played by eIF3 (Guan et al., 2017).

\subsection{The intricate cooperation among the three branches of the UPR}

While PERK acts mainly on global translation levels, and then indirectly on transcription via ATF4, the response elicited by IRE1 and ATF6 occurs predominantly at the transcriptional level. The most evolutionarily conserved branch of the UPR is activated by IRE1 (Cox et al., 1993), an ER-transmembrane endonuclease with the RNase domain facing the cytoplasm. Upon ER accumulation of unfolded proteins, IRE1 undergoes trans-autophosphorylation and dimerisation, and is then able to splice the Xbp1 mRNA into Xbp1s, which encodes the functional version of transcription factor XBP1 (Calfon et al., 2002). Interestingly, cytoplasmic splicing not only provides the correctly spliced version of Xbp1, but also increases its stability when paired with low levels of translation (Majumder et al., 2012). This results in cytoplasmic accumulation of Xbp1s mRNA during the early UPR, ready to be translated as soon as translational repression is relaxed in later stages of the response (Majumder et al., 2012). After relocating to the nucleus, XBP1 enhances the transcription of its own gene as well as some ER-target genes including EDEM1 and chaperones of the DnaJ/Hsp40 family (Acosta-Alvear et al., 2007). EDEM1, together with other proteins of the EDEM family, is involved in the targeting of terminally misfolded glycoproteins for ER-associated protein degradation (ERAD), a process in which proteins are retro-transported to the cytosol, ubiquinated, and degraded by the proteasome (Hwang \& Qi, 2018). Importantly, IRE1 activation also leads to promiscuous endoribonuclease activity, resulting in mRNA decay at the ER membrane, a process called regulated IRE1-dependent decay (RIDD), which helps to further reduce the protein load in the ER (Hollien et al., 2009; Hollien \& Weissman, 2006).

The remaining arm of the UPR is activated when, upon accumulation of unfolded proteins, BiP disassociates from ATF6 thus exposing its two Golgi localization sequences. As a result, ATF6 is relocated to the Golgi, where the transmembrane and luminal domains can be cleaved by Golgi-located Site 1 and Site 2 Proteases (S1P and S2P)(Hillary \& FitzGerald, 2018). The cytoplasmic domain is then released and can enter the nucleus, where it enhances the expression of-among several other stress-related targets-EDEM1, ER-resident protein disulfide isomerase PDIA6, and BiP itself (Shoulders et al., 2013; Vekich, Belmont, Thuerauf, \& Glembotski, 2012). In addition to proteotoxic stress, the UPR can be induced by an increase in sphingolipids or by general lipid bilayer stress (LBS). Although the main effectors-IRE1, ATF6, and PERK - are still involved, the method by which the stress is sensed and the downstream effects are different. In response to LBS, ATF6 induces transcription of lipid biosynthetic and metabolic genes, but not ER chaperones (F. H. Fun \& Thibault, 2019; Tam et al., 2018). It has been proposed that these differences might be controlled through post-translational modifications on ATF6, providing an important additional layer of regulation during the UPR (Tam et al., 2018).

Several positive reinforcement mechanisms exist among the three branches of the UPR. For example, it has been reported that both the expression of ATF6 and its relocation to the Golgi are enhanced by the PERK/ATF4 pathway (Teske et al., 2011). In addition, ATF6 promotes transcription of Xbp1 thus boosting the IRE1 arm of the UPR (Yoshida, Matsui, Yamamoto, Okada, \& Mori, 2001).

However, the PERK pathway also seems to have a restraining effect on the other two arms of the UPR by attenuating the induction of a set of ATF6 and XBP1 targets, particularly sterol and lipid biosynthesis genes, at both the transcription and the translation levels (Gonen et al., 2019). ATF6-target PDIA6 might also play a role in limiting the levels of IRE1 activation (Eletto, Eletto, Dersh, Gidalevitz, \& Argon, 2014). In addition, in case of persistence of the ER stress conditions, PERK seems to steer the cell response away from adaptive strategies (such as ERAD and RIDD) and toward apoptosis by eliciting loss of activation of IRE1 through the phosphatase RPAP2 (Chang et al., 2018). 
The coordination among different UPR pathways is therefore very intricately regulated, in an effort to achieve an appropriate and effective response. Aberrant regulation of the UPR, or an imbalance among the pathways, particularly in situations that require the production and/or secretion of a large amount of proteins, can contribute to the pathogenesis of several diseases. For example, the IRE1 and PERK pathways need to be carefully balanced to avoid aberrant adipocyte differentiation, while disruption of any of the UPR arms can lead to the insurgence of diabetic states (Wang \& Kaufman, 2012). Moreover, chronic PERK hyperactivation leads to neurodegeneration, and indeed compounds that attenuate phospho-eIF2 $\alpha$-mediated translational repression were found to have a neuroprotective effect on mice models of dementia (Halliday et al., 2017). In general, the use of small molecules that target the UPR at different stages is currently being investigated at multiple levels and for a variety of diseases (Hetz, Axten, \& Patterson, 2019). In particular, since the UPR is critical for tumor cell proliferation and tumor growth, it represents a promising path to explore for cancer therapeutics.

\section{5 | TARGETING THE STRESS RESPONSE IN CANCER THERAPY}

Cells within the tumor microenvironment are exposed to severe sources of stress. Rapid proliferation creates a crowded environment where cells have to survive in conditions of hypoxia, nutrient deprivation, metabolic dysfunction enhancing the generation of ROS, metabolic stress, and even mechanical stress (Chen \& Xie, 2018; Liou \& Storz, 2010; Wang et al., 2017). The very fact that cancer cells are able to thrive within this environment shows an extraordinary capability of adaptation. Crucially, cancer cells must sustain very demanding rates of protein production, which often results in the accumulation of misfolded proteins in the ER and consequent activation of the UPR, as detailed above. Whereas noncancerous cells shut down global protein synthesis to clear the backlog of misfolded proteins, cancer cells have adapted to synthesize proteins in the presence of low level UPR activation by taking advantage of UPR regulatory mechanisms, such as the PERK pathway. For example, the phosphorylation of eIF2 $\alpha$ drives the adaptive response in aggressive prostate cancer (Nguyen et al., 2018) and translational reprogramming in malignant melanoma enhances ATF4 expression to promote metastasis and chemotherapeutic resistance (Falletta et al., 2017). Furthermore, ATF4 has been shown to function cooperatively with the oncogene MYC to limit the expression of proteins that are targeted to the ER, minimizing ER stress to levels that promote tumor survival and progression of lymphoma (Tameire et al., 2019).

Modulation and exploitation of the UPR has therefore been identified as a potential target leading to the development of a number of different therapeutic compounds (Wang, Law, Castellano, \& Law, 2018). Indeed, cancers characterized by a high basal level of ER stress, like multiple myeloma (MM), are typically treated with proteasome inhibitors to induce excessive ER stress and activate cell death pathways. Importantly, the absence of XBP1 was shown to enhance MM chemotherapeutic resistance (Leung-Hagesteijn et al., 2013), suggesting that targeting different pathways simultaneously could be highly advantageous.

As PERK has been shown to be required for metastatic progression (Feng et al., 2017), PERK inhibitors have been developed to specifically block the translational reprogramming capacity of tumor cells, although their clinical application has been prevented by off-target toxicity that is likely due to the extensive and essential role of PERK in noncancerous secretory tissue such as the pancreas (Gao et al., 2012; Harding et al., 2001). However, direct targeting downstream of PERK signaling, for example, at the level of eIF2 $\alpha$ phosphorylation and translational reprogramming, provides a window of opportunity for the development of novel therapies. As described earlier in the review, the phosphorylation of eIF $2 \alpha$ inhibits global protein synthesis and promotes translational reprogramming by sequestering its GEF eIF2B. Relieving eIF2B inhibition with the small molecule ISRIB (Sekine et al., 2015; Sidrauski et al., 2015) reduces tumor cell adaptation to restrict growth and invasion of melanoma (Falletta et al., 2017) and aggressive prostate cancer (Nguyen et al., 2018). While the targeting of eIF2 $\alpha$ signaling with ISRIB has shown extremely positive antitumor activity (Falletta et al., 2017; Nguyen et al., 2018), ISRIB only inhibits the ISR when eIF2 $\alpha$ phosphorylation is below a critical threshold (Rabouw et al., 2019) which is likely cell- and tissue-type specific. More importantly, the relatively poor solubility of ISRIB is likely to limit its clinical application. Nonetheless, these studies illustrate that chemical targeting of these pathways is a viable option to limit cancer cell proliferation and adaptation to stress, and more effort must be made to identify other compounds that target these pathways.

Genome scale CRISPR-Cas9 screens are revolutionizing cancer research as they allow for the identification of swathes of genes that appear critical for cancer cell survival and cell fitness, thus highlighting an array of potential therapeutic targets (Behan et al., 2019; S. Chen et al., 2015; Yamauchi et al., 2018). Gene ontology (GO) annotation of genes that are deemed essential for cancer cell fitness (Table S1) (Behan et al., 2019) shows that a number of these genes 
(a) Cancer fitness genes

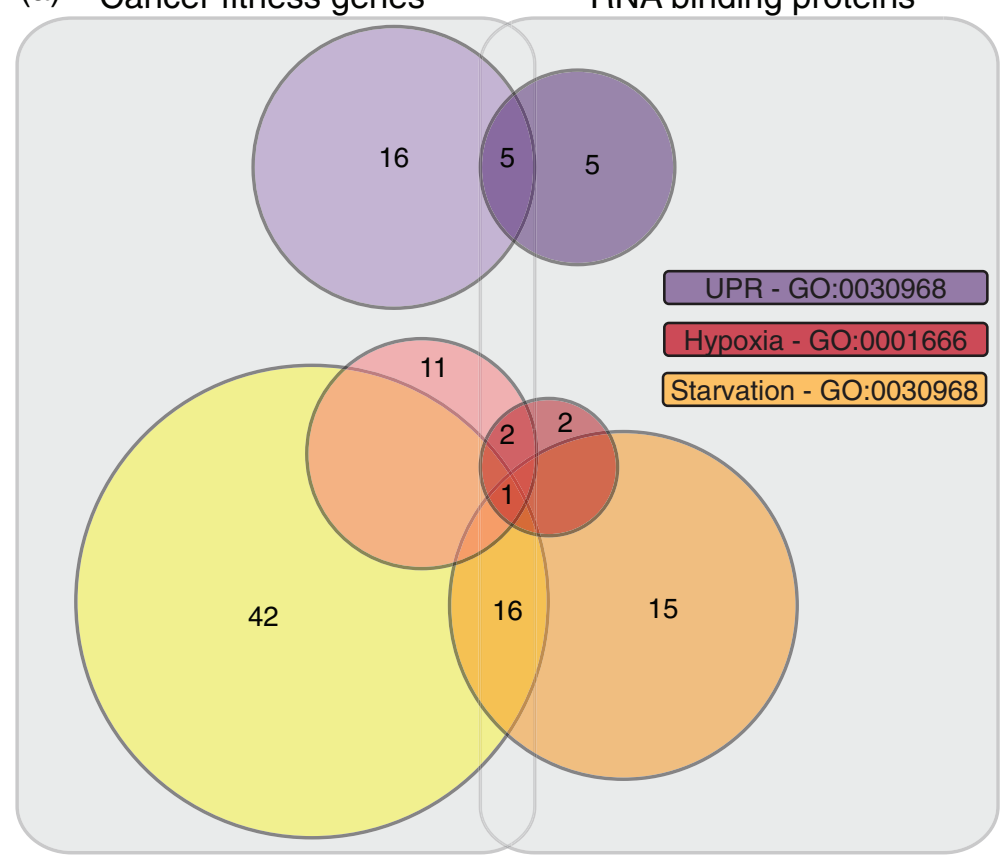

(b)

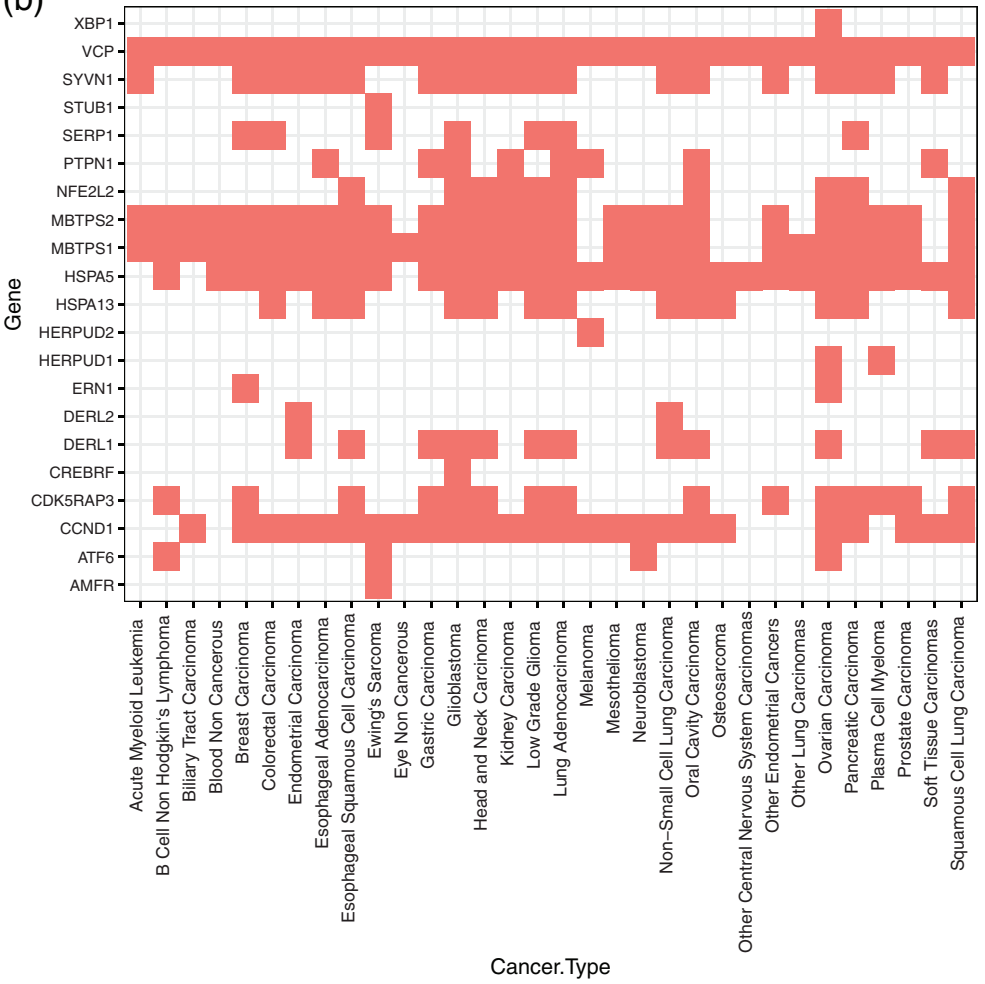

F I G U RE 4 Schematic representation of GO annotation of cancer fitness genes and RBPs.

(a) Number of cancer fitness genes (left box, data from Behan et al., 2019) and RBPs (right box, data from Queiroz et al., 2019; Trendel et al., 2019) annotated with GO terms for UPR (purple), starvation (red), and hypoxia (yellow/orange). The overlap between Venn diagrams indicates the number of genes listed as both cancer fitness genes and RBPs, annotated with each of the GO terms mentioned above. (b) Heatmap showing a subset of cancer fitness genes involved in the UPR (y axis, $n=21$ for GO:0030968) and their importance across cancer types (x axis). Red = important for cancer fitness; white $=$ not important for cancer fitness. GO, gene ontology; RBPs, RNA-binding proteins

(93 out of 7,470 cancer fitness genes) are associated with the cellular response to starvation, hypoxia, or the UPR (Figure 4a) adding support to the notion that cancer cells are able to take advantage of evolutionarily conserved stress response pathways to promote survival. The overlap was particularly striking for the UPR, where $20 \%$ of all the human proteins included in the GO term (GO:0030968) were also found to be essential in the fitness screen. The apparent requirement of the genes varies in different cancer types (Figure 4b), possibly reflecting tissue- and cancer-type specific dependencies that could potentially be exploited for therapeutic intervention. However, due to the inherent issues associated with this type of screens, it will be necessary to validate the findings of these studies at the single gene level. Importantly, as extensively reviewed previously and reiterated in the sections above, RNA-binding proteins are 
emerging as critical regulators of the cell response to stress and of cancer adaptation (Harvey et al., 2017). Accordingly, GO annotation of all proteins currently annotated as RBPs (taken from [Queiroz et al., 2019; Trendel et al., 2019]) shows that a number of RBPs have already been associated with the cellular response to starvation, hypoxia, or the UPR (Figure 4a, Table S1), and at least half of these proteins were found to be essential in the cancer fitness screen (Behan et al., 2019).

These observations contribute to the intriguing suggestion that cancer cells might rely on the modulation of the expression or the RNA-binding activity of some stress-related RBPs, possibly to regulate specific mRNA translation/ repression. Therefore, the regulation of the RNA-binding activity of RBPs represents a potentially underappreciated aspect of the cell adaptation response to stress and warrants further investigation and validation in the context of cancer survival and proliferation.

\section{6 | CONCLUSIONS}

Considering the remarkable progress that has been made toward understanding the cell response to stress and the related post-transcriptional regulation events, it is important to reflect on the important challenges that remain to be addressed. In physiological conditions and in disease, different types of stress are likely to be encountered simultaneously, not least because one frequently arises as a consequence of another. Defining the extent of the overlap among responses to different stimuli, as well as the cross-talk among distinct pathways within the same response, represents another key challenge. Moreover, it is not yet completely clear how and when the transition among different phases of the stress response is determined and what measures are undertaken to ensure that the cell maintains maneuverability until the commitment to a specific fate.

Techniques that allow for the dynamic interrogation of the transcriptome, translatome, and proteome provide ever increasing resolution into the molecular details underlying the complexity of the stress response. Similarly, as RBPisolating techniques (Castello et al., 2013; Queiroz et al., 2019; Trendel et al., 2019) become more sensitive and more applicable to dynamic contexts, our understanding of the involvement of RBPs in the stress response will likely expand. Since cancer cells are known to take advantage of the stress response in several ways, especially the UPR, in order to proliferate in adverse conditions, improved understanding of these processes may inform the design of novel cancer therapeutics.

\section{CONFLICT OF INTEREST}

The authors have declared no conflicts of interest for this article.

\section{AUTHOR CONTRIBUTIONS}

Mariavittoria Pizzinga: Conceptualization-equal; writing-original draft-lead. Robert Harvey: Conceptualizationequal; writing-original draft-supporting. Gavin Garland: Writing-original draft-supporting. Ryan Mordue: Writingoriginal draft-supporting. Veronica Dezi: Writing-original draft-equal. Manasa Ramakrishna: Writing-original draftsupporting. Aristeidis Sfakianos: Writing-original draft-supporting. Mie Monte: Writing-original draft-equal. Thomas Mulroney: Writing-original draft-supporting. Tuija Poyry: Writing-original draft-supporting. Anne Willis: Conceptualization-equal; funding acquisition-lead; project administration-lead; supervision-lead; writing-review \& editing-supporting

\section{ORCID}

Anne E. Willis (1D https://orcid.org/0000-0002-1470-8531

\section{RELATED WIRES ARTICLES}

$\underline{\text { Trans-acting translational regulatory RNA binding proteins. }}$

\section{REFERENCES}

Anderson, P., \& Ivanov, P. (2014). tRNA fragments in human health and disease. FEBS Letters, 588(23), 4297-4304. https://doi.org/10.1016/j. febslet.2014.09.001 
Acosta-Alvear, D., Zhou, Y., Blais, A., Tsikitis, M., Lents, N. H., Arias, C., ... Dynlacht, B. D. (2007). XBP1 controls diverse cell type- and condition-specific transcriptional regulatory networks. Molecular Cell, 27(1), 53-66. https://doi.org/10.1016/J.MOLCEL.2007.06.011

Adomavicius, T., Guaita, M., Zhou, Y., Jennings, M. D., Latif, Z., Roseman, A. M., \& Pavitt, G. D. (2019). The structural basis of translational control by eIF2 phosphorylation. Nature Communications, 10(1), 2136 https://doi.org/10.1038/s41467-019-10167-3.

Agris, P. F., Vendeix, F. A. P., \& Graham, W. D. (2007). tRNA's wobble decoding of the genome: 40 years of modification. Journal of Molecular Biology, 366(1), 1-13. https://doi.org/10.1016/j.jmb.2006.11.046

Anders, M., Chelysheva, I., Goebel, I., Trenkner, T., Zhou, J., Mao, Y., ... Ignatova, Z. (2018). Dynamic m6A methylation facilitates mRNA triaging to stress granules. Life Science Alliance, 1(4), e201800113. https://doi.org/10.26508/LSA.201800113

Aulas, A., Fay, M. M., Lyons, S. M., Achorn, C. A., Kedersha, N., Anderson, P., \& Ivanov, P. (2017). Stress-specific differences in assembly and composition of stress granules and related foci. Journal of Cell Science, 130(5), 927-937. https://doi.org/10.1242/jcs.199240

Begley, U., Sosa, M. S., Avivar-Valderas, A., Patil, A., Endres, L., Estrada, Y., ... Begley, T. (2013). A human tRNA methyltransferase 9-like protein prevents tumour growth by regulating LIN9 and HIF1- $\alpha$. EMBO Molecular Medicine, 5(3), 366-383. https://doi.org/10.1002/ emmm.201201161

Behan, F. M., Iorio, F., Picco, G., Gonçalves, E., Beaver, C. M., Migliardi, G., ... Garnett, M. J. (2019). Prioritization of cancer therapeutic targets using CRISPR-Cas9 screens. Nature, 568(7753), 511-516 https://doi.org/10.1038/s41586-019-1103-9.

Bergeron, J., Benlimame, N., Zeng-Rong, N., Xiao, D., Scrivens, P. J., Koromilas, A. E., \& Alaoui-Jamali, M. A. (2000). Identification of the interferon-inducible double-stranded RNA-dependent protein kinase as a regulator of cellular response to bulky adducts. Cancer Research, 60(24), 6800-6804. Retrieved from. http://www.ncbi.nlm.nih.gov/pubmed/11156368

Blanco, S., Dietmann, S., Flores, J. V., Hussain, S., Kutter, C., Humphreys, P., ... Frye, M. (2014). Aberrant methylation of tRNAs links cellular stress to neuro-developmental disorders. The EMBO Journal, 33(18), 2020-2039. https://doi.org/10.15252/embj.201489282

Boccaletto, P., Machnicka, M. A., Purta, E., Piątkowski, P., Bagiński, B., Wirecki, T. K., ... Bujnicki, J. M. (2018). MODOMICS: A database of RNA modification pathways. 2017 update. Nucleic Acids Research, 46(D1), D303-D307 https://doi.org/10.1093/nar/gkx1030.

Bou-Nader, C., Gordon, J. M., Henderson, F. E., \& Zhang, J. (2019). The search for a PKR code-differential regulation of protein kinase R activity by diverse RNA and protein regulators. RNA (New York, N.Y.), 25(5), 539-556. https://doi.org/10.1261/rna.070169.118

Buttgereit, F., \& Brand, M. D. (1995). A hierarchy of ATP-consuming processes in mammalian cells. The Biochemical Journal, 312(Pt 1), 163-167. https://doi.org/10.1042/bj3120163

Campbell, S. G., Hoyle, N. P., \& Ashe, M. P. (2005). Dynamic cycling of eIF2 through a large eIF2B-containing cytoplasmic body: Implications for translation control. The Journal of Cell Biology, 170(6), 925-934. https://doi.org/10.1083/jcb.200503162

Carlberg, U., Nilsson, A., \& Nygard, O. (1990). Functional properties of phosphorylated elongation factor 2. European Journal of Biochemistry, 191(3), 639-645. https://doi.org/10.1111/j.1432-1033.1990.tb19169.x

Castello, A., Horos, R., Strein, C., Fischer, B., Eichelbaum, K., Steinmetz, L. M., ... Hentze, M. W. (2013). System-wide identification of RNAbinding proteins by interactome capture. Nature Protocols, 8(3), 491-500. https://doi.org/10.1038/nprot.2013.020

Chan, C. T. Y., Deng, W., Li, F., DeMott, M. S., Babu, I. R., Begley, T. J., \& Dedon, P. C. (2015). Highly predictive reprogramming of tRNA modifications is linked to selective expression of codon-biased genes. Chemical Research in Toxicology, 28(5), 978-988. https://doi.org/10. 1021/acs.chemrestox.5b00004

Chan, C. T. Y., Pang, Y. L. J., Deng, W., Babu, I. R., Dyavaiah, M., Begley, T. J., \& Dedon, P. C. (2012). Reprogramming of tRNA modifications controls the oxidative stress response by codon-biased translation of proteins. Nature Communications, 3(1), 937. https://doi.org/10. $1038 /$ ncomms 1938

Chang, T.-K., Lawrence, D. A., Lu, M., Tan, J., Harnoss, J. M., Marsters, S. A., ... Ashkenazi, A. (2018). Coordination between two branches of the unfolded protein response determines apoptotic cell fate. Molecular Cell, 71(4), 629-636.e5. https://doi.org/10.1016/j.molcel.2018. 06.038

Chen, J.-J. (2014). Translational control by heme-regulated eIF2 $\alpha$ kinase during erythropoiesis. Current Opinion in Hematology, 21(3), 172-178. https://doi.org/10.1097/MOH.0000000000000030

Chen, M., \& Xie, S. (2018). Therapeutic targeting of cellular stress responses in cancer. Thoracic Cancer, 9(12), 1575-1582. https://doi.org/10. $1111 / 1759-7714.12890$

Chen, S., Sanjana, N. E., Zheng, K., Shalem, O., Lee, K., Shi, X., ... Sharp, P. A. (2015). Genome-wide CRISPR screen in a mouse model of tumor growth and metastasis. Cell, 160(6), 1246-1260. https://doi.org/10.1016/j.cell.2015.02.038

Cole, C., Sobala, A., Lu, C., Thatcher, S. R., Bowman, A., Brown, J. W. S., ... Hutvagner, G. (2009). Filtering of deep sequencing data reveals the existence of abundant dicer-dependent small RNAs derived from tRNAs. RNA, 15(12), 2147-2160. https://doi.org/10.1261/rna. 1738409

Cozen, A. E., Quartley, E., Holmes, A. D., Hrabeta-Robinson, E., Phizicky, E. M., \& Lowe, T. M. (2015). ARM-seq: AlkB-facilitated RNA methylation sequencing reveals a complex landscape of modified tRNA fragments. Nature Methods, 12(9), 879-884. https://doi.org/10. 1038/nmeth.3508

Darnell, A. M., Subramaniam, A. R., \& O'Shea, E. K. (2018). Translational control through differential ribosome pausing during amino acid limitation in mammalian cells. Molecular Cell, 71(2), 229-243.e11. https://doi.org/10.1016/j.molcel.2018.06.041

de Crécy-Lagard, V., Boccaletto, P., Mangleburg, C. G., Sharma, P., Lowe, T. M., Leidel, S. A., \& Bujnicki, J. M. (2019). Matching tRNA modifications in humans to their known and predicted enzymes. Nucleic Acids Research, 47(5), 2143-2159. https://doi.org/10.1093/nar/gkz011

de la Parra, C., Ernlund, A., Alard, A., Ruggles, K., Ueberheide, B., \& Schneider, R. J. (2018). A widespread alternate form of cap-dependent mRNA translation initiation. Nature Communications, 9(1), 3068. https://doi.org/10.1038/s41467-018-05539-0 
Dever, T. E., \& Green, R. (2012). The elongation, termination, and recycling phases of translation in eukaryotes. Cold Spring Harbor Perspectives in Biology, 4(7), a013706 https://doi.org/10.1101/cshperspect.a013706.

Dhakal, R., Tong, C., Anderson, S., Kashina, A. S., Cooperman, B., \& Bau, H. H. (2019). Dynamics of intracellular stress-induced tRNA trafficking. Nucleic Acids Research, 47(4), 2002-2010 https://doi.org/10.1093/nar/gky1208.

Díaz-Villanueva, J. F., Díaz-Molina, R., \& García-González, V. (2015). Protein folding and mechanisms of Proteostasis. International Journal of Molecular Sciences, 16(8), 17193-17230. https://doi.org/10.3390/ijms160817193

Donnelly, N., Gorman, A. M., Gupta, S., \& Samali, A. (2013). The eIF2 $\alpha$ kinases: Their structures and functions. Cellular and Molecular Life Sciences, 70(19), 3493-3511. https://doi.org/10.1007/s00018-012-1252-6

Dorrello, N. V., Peschiaroli, A., Guardavaccaro, D., Colburn, N. H., Sherman, N. E., \& Pagano, M. (2006). S6K1- and betaTRCP-mediated degradation of PDCD4 promotes protein translation and cell growth. Science (New York, N.Y.), 314(5798), 467-471. https://doi.org/10.1126/ science.1130276

Edupuganti, R. R., Geiger, S., Lindeboom, R. G. H., Shi, H., Hsu, P. J., Lu, Z., ... Vermeulen, M. (2017). N6-methyladenosine (m6A) recruits and repels proteins to regulate mRNA homeostasis. Nature Structural \& Molecular Biology, 24(10), 870-878. https://doi.org/10.1038/ nsmb.3462

Eletto, D., Eletto, D., Dersh, D., Gidalevitz, T., \& Argon, Y. (2014). Protein disulfide isomerase A6 controls the decay of IRE1 $\alpha$ signaling via disulfide-dependent association. Molecular Cell, 53(4), 562-576. https://doi.org/10.1016/j.molcel.2014.01.004

Elfakess, R., \& Dikstein, R. (2008). A translation initiation element specific to mRNAs with very short $5^{\prime}$ UTR that also regulates transcription. PLoS One, 3(8), e3094. https://doi.org/10.1371/journal.pone.0003094

Emara, M. M., Ivanov, P., Hickman, T., Dawra, N., Tisdale, S., Kedersha, N., ... Anderson, P. (2010). Angiogenin-induced tRNA-derived stress-induced RNAs promote stress-induced stress granule assembly. Journal of Biological Chemistry, 285(14), 10959-10968. https://doi. org/10.1074/jbc.M109.077560

Endres, L., Begley, U., Clark, R., Gu, C., Dziergowska, A., Małkiewicz, A., ... Begley, T. J. (2015). Alkbh8 regulates Selenocysteine-protein expression to protect against reactive oxygen species damage. PLoS One, 10(7), e0131335. https://doi.org/10.1371/journal.pone.0131335

Erales, J., Marchand, V., Panthu, B., Gillot, S., Belin, S., Ghayad, S. E., ... Diaz, J.-J. (2017). Evidence for rRNA 2'-O-methylation plasticity: Control of intrinsic translational capabilities of human ribosomes. Proceedings of the National Academy of Sciences of the United States of America, 114(49), 12934-12939 https://doi.org/10.1073/pnas.1707674114.

Falletta, P., Sanchez-Del-Campo, L., Chauhan, J., Effern, M., Kenyon, A., Kershaw, C. J., ... Goding, C. R. (2017). Translation reprogramming is an evolutionarily conserved driver of phenotypic plasticity and therapeutic resistance in melanoma. Genes \& Development, 31(1), 18-33 https://doi.org/10.1101/gad.290940.116.

Fawcett, T. W., Martindale, J. L., Guyton, K. Z., Hai, T., \& Holbrook, N. J. (1999). Complexes containing activating transcription factor (ATF)/cAMP-responsive-element-binding protein (CREB) interact with the CCAAT/enhancer-binding protein (C/EBP)-ATF composite site to regulate Gadd153 expression during the stress response. The Biochemical Journal, 339(Pt 1), 135-141. Retrieved from. http://www. ncbi.nlm.nih.gov/pubmed/10085237

Feng, Y.-X., Jin, D. X., Sokol, E. S., Reinhardt, F., Miller, D. H., \& Gupta, P. B. (2017). Cancer-specific PERK signaling drives invasion and metastasis through CREB3L1. Nature Communications, 8(1), 1079. https://doi.org/10.1038/s41467-017-01052-y

Fu, H., Feng, J., Liu, Q., Sun, F., Tie, Y., Zhu, J., ... Zheng, X. (2009). Stress induces tRNA cleavage by angiogenin in mammalian cells. FEBS Letters, 583(2), 437-442. https://doi.org/10.1016/j.febslet.2008.12.043

Fun, X. H., \& Thibault, G. (2019). Lipid bilayer stress and proteotoxic stress-induced unfolded protein response deploy divergent transcriptional and non-transcriptional programmes. Biochimica et Biophysica Acta (BBA) - Molecular and Cell Biology of Lipids, S1388-1981(19), 30062-9. https://doi.org/10.1016/J.BBALIP.2019.04.009

Gao, Y., Sartori, D. J., Li, C., Yu, Q.-C., Kushner, J. A., Simon, M. C., \& Diehl, J. A. (2012). PERK is required in the adult pancreas and is essential for maintenance of glucose homeostasis. Molecular and Cellular Biology, 32(24), 5129-5139 https://doi.org/10.1128/MCB. 01009-12.

Gingold, H., \& Pilpel, Y. (2011). Determinants of translation efficiency and accuracy. Molecular Systems Biology, 7, 481. https://doi.org/10. 1038/msb.2011.14

Gkatza, N. A., Castro, C., Harvey, R. F., Heiß, M., Popis, M. C., Blanco, S., ... Frye, M. (2019). Cytosine-5 RNA methylation links protein synthesis to cell metabolism. PLoS Biology, 17(6), e3000297 https://doi.org/10.1371/journal.pbio.3000297.

Godet, A.-C., David, F., Hantelys, F., Tatin, F., Lacazette, E., Garmy-Susini, B., \& Prats, A.-C. (2019). IRES trans-acting factors, key actors of the stress response. International Journal of Molecular Sciences, 20(4), 924. https://doi.org/10.3390/ijms20040924.

Gogakos, T., Brown, M., Garzia, A., Meyer, C., Hafner, M., \& Tuschl, T. (2017). Characterizing expression and processing of precursor and mature human tRNAs by hydro-tRNAseq and PAR-CLIP. Cell Reports, 20(6), 1463-1475. https://doi.org/10.1016/j.celrep.2017.07.029

Goll, M. G., Kirpekar, F., Maggert, K. A., Yoder, J. A., Hsieh, C.-L., Zhang, X., ... Bestor, T. H. (2006). Methylation of tRNA Asp by the DNA Methyltransferase homolog Dnmt2. Science, 311(5759), 395-398. https://doi.org/10.1126/science.1120976

Gonen, N., Sabath, N., Burge, C. B., \& Shalgi, R. (2019). Widespread PERK-dependent repression of ER targets in response to ER stress. Scientific Reports, 9(1), 4330 https://doi.org/10.1038/s41598-019-38705-5.

Goodarzi, H., Liu, X., Nguyen, H. C. B., Zhang, S., Fish, L., \& Tavazoie, S. F. (2015). Endogenous tRNA-derived fragments suppress breast Cancer progression via YBX1 displacement. Cell, 161(4), 790-802. https://doi.org/10.1016/j.cell.2015.02.053

Gordiyenko, Y., Llácer, J. L., \& Ramakrishnan, V. (2019). Structural basis for the inhibition of translation through eIF2 $\alpha$ phosphorylation. Nature Communications, 10(1), 2640 https://doi.org/10.1038/s41467-019-10606-1. 
Grootjans, J., Kaser, A., Kaufman, R. J., \& Blumberg, R. S. (2016). The unfolded protein response in immunity and inflammation. Nature Reviews Immunology, 16(8), 469-484. https://doi.org/10.1038/nri.2016.62

Guan, B.-J., van Hoef, V., Jobava, R., Elroy-Stein, O., Valasek, L. S., Cargnello, M., ... Hatzoglou, M. (2017). A unique ISR program determines cellular responses to chronic stress. Molecular Cell, 68(5), 885-900.e6. https://doi.org/10.1016/j.molcel.2017.11.007

Haimov, O., Sinvani, H., Martin, F., Ulitsky, I., Emmanuel, R., Tamarkin-Ben-Harush, A., ... Dikstein, R. (2017). Efficient and accurate translation initiation directed by TISU involves RPS3 and RPS10e binding and differential eukaryotic initiation factor 1A regulation. Molecular and Cellular Biology, 37(15), e00150-17. https://doi.org/10.1128/MCB.00150-17.

Halliday, M., Radford, H., Zents, K. A. M., Molloy, C., Moreno, J. A., Verity, N. C., ... Mallucci, G. R. (2017). Repurposed drugs targeting eIF2 $\alpha$-P-mediated translational repression prevent neurodegeneration in mice. Brain, 140(6), 1768-1783. https://doi.org/10.1093/brain/ awx074

Harding, H. P., Novoa, I., Zhang, Y., Zeng, H., Wek, R., Schapira, M., \& Ron, D. (2000). Regulated translation initiation controls stressinduced gene expression in mammalian cells. Molecular Cell, 6(5), 1099-1108. Retrieved from. http://www.ncbi.nlm.nih.gov/pubmed/ 11106749

Harding, H. P., Zeng, H., Zhang, Y., Jungries, R., Chung, P., Plesken, H., ... Ron, D. (2001). Diabetes mellitus and exocrine pancreatic dysfunction in Perk-/- mice reveals a role for translational control in secretory cell survival. Molecular Cell, 7(6), 1153-1163. https://doi. org/10.1016/S1097-2765(01)00264-7

Harding, H. P., Zhang, Y., Bertolotti, A., Zeng, H., \& Ron, D. (2000). Perk is essential for translational regulation and cell survival during the unfolded protein response. Molecular Cell, 5(5), 897-904. https://doi.org/10.1016/S1097-2765(00)80330-5

Harvey, R., Dezi, V., Pizzinga, M., \& Willis, A. E. (2017). Post-transcriptional control of gene expression following stress: The role of RNAbinding proteins. Biochemical Society Transactions, 45(4), 1007-1014. https://doi.org/10.1042/BST20160364

Harvey, R. F., Smith, T. S., Mulroney, T., Queiroz, R. M. L., Pizzinga, M., Dezi, V., ... Willis, A. E. (2018). Trans-acting translational regulatory RNA binding proteins. Wiley Interdisciplinary Reviews: RNA, 9(3), e1465. https://doi.org/10.1002/wrna.1465

Hellen, C. U. T., \& Sarnow, P. (2001). Internal ribosome entry sites in eukaryotic mRNA molecules. Genes \& Development, 15(13), 1593-1612. https://doi.org/10.1101/gad.891101

Hetz, C., Axten, J. M., \& Patterson, J. B. (2019). Pharmacological targeting of the unfolded protein response for disease intervention. Nature Chemical Biology, 15(8), 764-775 https://doi.org/10.1038/s41589-019-0326-2.

Hillary, R. F., \& FitzGerald, U. (2018). A lifetime of stress: ATF6 in development and homeostasis. Journal of Biomedical Science, $25(1)$, 48. https://doi.org/10.1186/s12929-018-0453-1

Hinnebusch, A. G. (1984). Evidence for translational regulation of the activator of general amino acid control in yeast. Proceedings of the National Academy of Sciences of the United States of America, 81(20), 6442-6446 https://doi.org/10.1073/pnas.81.20.6442.

Hodgson, R. E., Varanda, B. A., Ashe, M. P., Allen, K. E., \& Campbell, S. G. (2019). Cellular eIF2B subunit localization: Implications for the integrated stress response and its control by small molecule drugs. Molecular Biology of the Cell, 30(8), 942-958 https://doi.org/10.1091/mbc.E18-08-0538.

Hollien, J., Lin, J. H., Li, H., Stevens, N., Walter, P., \& Weissman, J. S. (2009). Regulated Ire1-dependent decay of messenger RNAs in mammalian cells. The Journal of Cell Biology, 186(3), 323-331. https://doi.org/10.1083/jcb.200903014

Hollien, J., \& Weissman, J. S. (2006). Decay of endoplasmic reticulum-localized mRNAs during the unfolded protein response. Science (New York, N.Y.), 313(5783), 104-107. https://doi.org/10.1126/science.1129631

Holz, M. K., Ballif, B. A., Gygi, S. P., \& Blenis, J. (2005). mTOR and S6K1 mediate assembly of the translation Preinitiation complex through dynamic protein interchange and ordered phosphorylation events. Cell, 123(4), 569-580. https://doi.org/10.1016/J.CELL.2005.10.024

Huang, H.-Y., \& Hopper, A. (2016). Multiple layers of stress-induced regulation in tRNA biology. Life, 6(2), 16. https://doi.org/10.3390/ life 6020016

Hwang, J., \& Qi, L. (2018). Quality control in the endoplasmic reticulum: Crosstalk between ERAD and UPR pathways. Trends in Biochemical Sciences, 43(8), 593-605. https://doi.org/10.1016/J.TIBS.2018.06.005

Inglis, A. J., Masson, G. R., Shao, S., Perisic, O., McLaughlin, S. H., Hegde, R. S., \& Williams, R. L. (2019). Activation of GCN2 by the ribosomal P-stalk. Proceedings of the National Academy of Sciences of the United States of America, 116(11), 4946-4954 https://doi. org/10.1073/pnas.1813352116.

Iurlaro, R., \& Muñoz-Pinedo, C. (2016). Cell death induced by endoplasmic reticulum stress. The FEBS Journal, 283(14), 2640-2652. https:// doi.org/10.1111/febs.13598

Ivanov, P., Emara, M. M., Villen, J., Gygi, S. P., \& Anderson, P. (2011). Angiogenin-induced tRNA fragments inhibit translation initiation. Molecular Cell, 43(4), 613-623. https://doi.org/10.1016/j.molcel.2011.06.022

Jain, S., Wheeler, J. R., Walters, R. W., Agrawal, A., Barsic, A., \& Parker, R. (2016). ATPase-modulated stress granules contain a diverse proteome and substructure. Cell, 164(3), 487-498. https://doi.org/10.1016/j.cell.2015.12.038

Jang, S. K., Pestova, T. V., Hellen, C. U., Witherell, G. W., \& Wimmer, E. (1990). Cap-independent translation of picornavirus RNAs: Structure and function of the internal ribosomal entry site. Enzyme, 44(1-4), 292-309. Retrieved from. http://www.ncbi.nlm.nih.gov/pubmed/ 1966843

Jennings, M. D., Zhou, Y., Mohammad-Qureshi, S. S., Bennett, D., \& Pavitt, G. D. (2013). eIF2B promotes eIF5 dissociation from eIF2*GDP to facilitate guanine nucleotide exchange for translation initiation. Genes \& Development, 27(24), 2696-2707. https://doi.org/10.1101/gad. 231514.113 
Jennings, M. D., Kershaw, C. J., Adomavicius, T., \& Pavitt, G. D. (2017). Fail-safe control of translation initiation by dissociation of eIF2 $\alpha$ phosphorylated ternary complexes. eLife, 6, e24542. https://doi.org/10.7554/eLife.24542

Jennings, M. D., \& Pavitt, G. D. (2010). eIF5 has GDI activity necessary for translational control by eIF2 phosphorylation. Nature, 465(7296), 378-381. https://doi.org/10.1038/nature09003

Kashiwagi, K., Yokoyama, T., Nishimoto, M., Takahashi, M., Sakamoto, A., Yonemochi, M., ... Ito, T. (2019). Structural basis for eIF2B inhibition in integrated stress response. Science, 364(6439), 495-499 https://doi.org/10.1126/SCIENCE.AAW4104.

Kawaji, H., Nakamura, M., Takahashi, Y., Sandelin, A., Katayama, S., Fukuda, S., ... Hayashizaki, Y. (2008). Hidden layers of human small RNAs. BMC Genomics, 9(1), 157. https://doi.org/10.1186/1471-2164-9-157

Kenner, L. R., Anand, A. A., Nguyen, H. C., Myasnikov, A. G., Klose, C. J., McGeever, L. A., ... Frost, A. (2019). eIF2B-catalyzed nucleotide exchange and phosphoregulation by the integrated stress response. Science (New York, N.Y.), 364(6439), 491-495. https://doi.org/10. 1126/science.aaw2922

Khong, A., Matheny, T., Jain, S., Mitchell, S. F., Wheeler, J. R., \& Parker, R. (2017). The stress granule transcriptome reveals principles of mRNA accumulation in stress granules. Molecular Cell, 68(4), 808-820.e5. https://doi.org/10.1016/J.MOLCEL.2017.10.015

Kim, Y., Park, J., Kim, S., Kim, M., Kang, M.-G., Kwak, C., ... Kim, V. N. (2018). PKR senses nuclear and mitochondrial signals by interacting with endogenous double-stranded RNAs. Molecular Cell, 71(6), 1051-1063.e6. https://doi.org/10.1016/J.MOLCEL.2018.07.029

Kishimoto, K., Yoshida, S., Ibaragi, S., Yoshioka, N., Okui, T., Hu, G., \& Sasaki, A. (2012). Hypoxia-induced up-regulation of angiogenin, besides VEGF, is related to progression of oral cancer. Oral Oncology, 48(11), 1120-1127. https://doi.org/10.1016/j.oraloncology.2012. 05.009

Knight, J. R. P., Bastide, A., Roobol, A., Roobol, J., Jackson, T. J., Utami, W., ... Willis, A. E. (2015). Eukaryotic elongation factor 2 kinase regulates the cold stress response by slowing translation elongation. Biochemical Journal, 465(2), 227-238 https://doi.org/10.1042/ BJ20141014.

Kramer, E. B., \& Hopper, A. K. (2013). Retrograde transfer RNA nuclear import provides a new level of tRNA quality control in Saccharomyces cerevisiae. Proceedings of the National Academy of Sciences of the United States of America, 110(52), 21042-21047 https://doi. org/10.1073/pnas.1316579110.

Kucherenko, M. M., \& Shcherbata, H. R. (2018). miRNA targeting and alternative splicing in the stress response - events hosted by membrane-less compartments. Journal of Cell Science, 131(4), jcs202002. https://doi.org/10.1242/jcs.202002

Leppek, K., Das, R., \& Barna, M. (2018). Functional 5' UTR mRNA structures in eukaryotic translation regulation and how to find them. Nature Reviews Molecular Cell Biology, 19(3), 158-174. https://doi.org/10.1038/nrm.2017.103

Leung-Hagesteijn, C., Erdmann, N., Cheung, G., Keats, J. J., Stewart, A. K., Reece, D. E., ... Tiedemann, R. E. (2013). Xbp1s-negative tumor B cells and pre-plasmablasts mediate therapeutic proteasome inhibitor resistance in multiple myeloma. Cancer Cell, 24(3), 289-304. https://doi.org/10.1016/j.ccr.2013.08.009

Liou, G.-Y., \& Storz, P. (2010). Reactive oxygen species in cancer. Free Radical Research, 44(5), 479-496. https://doi.org/10.3109/ 10715761003667554

Lu, P. D., Harding, H. P., \& Ron, D. (2004). Translation reinitiation at alternative open reading frames regulates gene expression in an integrated stress response. The Journal of Cell Biology, 167(1), 27-33. https://doi.org/10.1083/jcb.200408003

Lyons, S. M., Achorn, C., Kedersha, N. L., Anderson, P. J., \& Ivanov, P. (2016). YB-1 regulates tiRNA-induced stress granule formation but not translational repression. Nucleic Acids Research, 44(14), 6949-6960. https://doi.org/10.1093/nar/gkw418

Lyons, S. M., Fay, M. M., Akiyama, Y., Anderson, P. J., \& Ivanov, P. (2017). RNA biology of angiogenin: Current state and perspectives. RNA Biology, 14(2), 171-178. https://doi.org/10.1080/15476286.2016.1272746

Ma, Y., \& Hendershot, L. M. (2003). Delineation of a negative feedback regulatory loop that controls protein translation during endoplasmic reticulum stress. The Journal of Biological Chemistry, 278(37), 34864-34873. https://doi.org/10.1074/jbc.M301107200

Majumder, M., Huang, C., Snider, M. D., Komar, A. A., Tanaka, J., Kaufman, R. J., ... Hatzoglou, M. (2012). A novel feedback loop regulates the response to endoplasmic reticulum stress via the cooperation of cytoplasmic splicing and mRNA translation. Molecular and Cellular Biology, 32(5), 992-1003. https://doi.org/10.1128/MCB.06665-11

Marcel, V., Catez, F., \& Diaz, J.-J. (2015). Ribosome heterogeneity in tumorigenesis: The rRNA point of view. Molecular \& Cellular Oncology, 2(3), e983755. https://doi.org/10.4161/23723556.2014.983755

McEwen, E., Kedersha, N., Song, B., Scheuner, D., Gilks, N., Han, A., ... Kaufman, R. J. (2005). Heme-regulated inhibitor kinase-mediated phosphorylation of eukaryotic translation initiation factor 2 inhibits translation, induces stress granule formation, and mediates survival upon arsenite exposure. The Journal of Biological Chemistry, 280(17), 16925-16933. https://doi.org/10.1074/jbc.M412882200

Meyer, K. D., Patil, D. P., Zhou, J., Zinoviev, A., Skabkin, M. A., Elemento, O., ... Jaffrey, S. R. (2015). 5' UTR m(6)a promotes capindependent translation. Cell, 163(4), 999-1010. https://doi.org/10.1016/j.cell.2015.10.012

Milisav, I., Poljšak, B., \& Ribarič, S. (2017). Reduced risk of apoptosis: Mechanisms of stress responses. Apoptosis, 22(2), 265-283. https://doi. org/10.1007/s10495-016-1317-3

Mitchell, S. A., Spriggs, K. A., Bushell, M., Evans, J. R., Stoneley, M., Le Quesne, J. P. C., ... Willis, A. E. (2005). Identification of a motif that mediates polypyrimidine tract-binding protein-dependent internal ribosome entry. Genes \& Development, 19(13), 1556-1571. https://doi. $\operatorname{org} / 10.1101 / \operatorname{gad} .339105$

Molliex, A., Temirov, J., Lee, J., Coughlin, M., Kanagaraj, A. P., Kim, H. J., ... Taylor, J. P. (2015). Phase separation by low complexity domains promotes stress granule assembly and drives pathological fibrillization. Cell, 163(1), 123-133. https://doi.org/10.1016/j.cell.2015. 09.015 
Nakamura, T., Furuhashi, M., Li, P., Cao, H., Tuncman, G., Sonenberg, N., ... Hotamisligil, G. S. (2010). Double-stranded RNA-dependent protein kinase links pathogen sensing with stress and metabolic homeostasis. Cell, 140(3), 338-348. https://doi.org/10.1016/j.cell.2010. 01.001

Nallagatla, S. R., Jones, C. N., Ghosh, S. K. B., Sharma, S. D., Cameron, C. E., Spremulli, L. L., \& Bevilacqua, P. C. (2013). Native tertiary structure and nucleoside modifications suppress tRNA's intrinsic ability to activate the innate immune sensor PKR. PLoS One, 8(3), e57905. https://doi.org/10.1371/journal.pone.0057905

Nguyen, H. G., Conn, C. S., Kye, Y., Xue, L., Forester, C. M., Cowan, J. E., ... Ruggero, D. (2018). Development of a stress response therapy targeting aggressive prostate cancer. Science Translational Medicine, 10(439), eaar2036. https://doi.org/10.1126/scitranslmed.aar2036

Niewidok, B., Igaev, M., Pereira da Graca, A., Strassner, A., Lenzen, C., Richter, C. P., ... Brandt, R. (2018). Single-molecule imaging reveals dynamic biphasic partition of RNA-binding proteins in stress granules. The Journal of Cell Biology, 217(4), 1303-1318. https://doi.org/10. $1083 /$ jcb.201709007

Novoa, I., Zhang, Y., Zeng, H., Jungreis, R., Harding, H. P., \& Ron, D. (2003). Stress-induced gene expression requires programmed recovery from translational repression. The EMBO Journal, 22(5), 1180-1187. https://doi.org/10.1093/emboj/cdg112

Oberacher, H., Mayr, B. M., \& Huber, C. G. (2004). Automated de novo sequencing of nucleic acids by liquid chromatography-tandem mass spectrometry. Journal of the American Society for Mass Spectrometry, 15(1), 32-42. https://doi.org/10.1016/j.jasms.2003.09.005

Ohira, T., \& Suzuki, T. (2011). Retrograde nuclear import of tRNA precursors is required for modified base biogenesis in yeast. Proceedings of the National Academy of Sciences of the United States of America, 108(26), 10502. https://doi.org/10.1073/PNAS.1105645108-10507.

Padrón, A., Iwasaki, S., \& Ingolia, N. T. (2019). Proximity RNA labeling by APEX-Seq reveals the Organization of Translation Initiation Complexes and Repressive RNA granules. Molecular Cell, 75(4), 875-887.e5. https://doi.org/10.1016/J.MOLCEL.2019.07.030

Pang, Y. L. J., Abo, R., Levine, S. S., \& Dedon, P. C. (2014). Diverse cell stresses induce unique patterns of tRNA up- and down-regulation: tRNA-seq for quantifying changes in tRNA copy number. Nucleic Acids Research, 42(22), e170. https://doi.org/10.1093/nar/gku945

Pavitt, G. D. (2018). Regulation of translation initiation factor eIF2B at the hub of the integrated stress response. Wiley Interdisciplinary Reviews: RNA, 9(6), e1491. https://doi.org/10.1002/WRNA.1491

Pavitt, G. D., \& Ron, D. (2012). New insights into translational regulation in the endoplasmic reticulum unfolded protein response. Cold Spring Harbor Perspectives in Biology, 4(6), a012278. https://doi.org/10.1101/cshperspect.a012278

Peidis, P., Papadakis, A. I., Muaddi, H., Richard, S., \& Koromilas, A. E. (2011). Doxorubicin bypasses the cytoprotective effects of eIF2 $\alpha$ phosphorylation and promotes PKR-mediated cell death. Cell Death and Differentiation, 18(1), 145-154. https://doi.org/10.1038/cdd.2010.76

Pelletier, J., \& Sonenberg, N. (1988). Internal initiation of translation of eukaryotic mRNA directed by a sequence derived from poliovirus RNA. Nature, 334(6180), 320-325. https://doi.org/10.1038/334320a0

Pereira, E. R., Liao, N., Neale, G. A., \& Hendershot, L. M. (2010). Transcriptional and post-transcriptional regulation of Proangiogenic factors by the unfolded protein response. PLoS One, 5(9), e12521. https://doi.org/10.1371/journal.pone.0012521

Pestova, T. V., \& Kolupaeva, V. G. (2002). The roles of individual eukaryotic translation initiation factors in ribosomal scanning and initiation codon selection. Genes \& Development, 16(22), 2906-2922. https://doi.org/10.1101/gad.1020902

Poljšak, B., \& Milisav, I. (2012). Clinical implications of cellular stress responses. Bosnian Journal of Basic Medical Sciences, 12(2), $122-126$. https://doi.org/10.17305/bjbms.2012.2510

Proud, C. G. (2015). Regulation and roles of elongation factor 2 kinase. Biochemical Society Transactions, 43(3), 328-332. https://doi.org/10. 1042/BST20140323

Qin, X., \& Sarnow, P. (2004). Preferential translation of internal ribosome entry site-containing mRNAs during the mitotic cycle in mammalian cells. Journal of Biological Chemistry, 279(14), 13721-13728. https://doi.org/10.1074/jbc.M312854200

Queiroz, R. M. L., Smith, T., Villanueva, E., Marti-Solano, M., Monti, M., Pizzinga, M., ... Lilley, K. S. (2019). Comprehensive identification of RNA-protein interactions in any organism using orthogonal organic phase separation (OOPS). Nature Biotechnology, 37(2), 169-178. https://doi.org/10.1038/s41587-018-0001-2

Rabouw, H. H., Langereis, M. A., Anand, A. A., Visser, L. J., de Groot, R. J., Walter, P., \& van Kuppeveld, F. J. M. (2019). Small molecule ISRIB suppresses the integrated stress response within a defined window of activation. Proceedings of the National Academy of Sciences of the United States of America, 116(6), 2097-2102 https://doi.org/10.1073/pnas.1815767116.

Reid, D. W., Chen, Q., Tay, A. S.-L., Shenolikar, S., \& Nicchitta, C. V. (2014). The unfolded protein response triggers selective mRNA release from the endoplasmic reticulum. Cell, 158(6), 1362-1374. https://doi.org/10.1016/j.cell.2014.08.012

Rendleman, J., Cheng, Z., Maity, S., Kastelic, N., Munschauer, M., Allgoewer, K., ... Vogel, C. (2018). New insights into the cellular temporal response to proteostatic stress. eLife, 7, e39054. https://doi.org/10.7554/eLife.39054

Riback, J. A., Katanski, C. D., Kear-Scott, J. L., Pilipenko, E. V., Rojek, A. E., Sosnick, T. R., ... Allan Drummond, D. (2017). Stress-triggered phase separation is an adaptive, evolutionarily tuned response article stress-triggered phase separation is an adaptive, evolutionarily tuned response. Cell, 168, 1028-1040.e19. https://doi.org/10.1016/j.cell.2017.02.027

Ries, R. J., Zaccara, S., Klein, P., Olarerin-George, A., Namkoong, S., Pickering, B. F., ... Jaffrey, S. R. (2019). m6A enhances the phase separation potential of mRNA. Nature, 571(7765), 424-428. https://doi.org/10.1038/s41586-019-1374-1

Ruvinsky, I., \& Meyuhas, O. (2006). Ribosomal protein S6 phosphorylation: From protein synthesis to cell size. Trends in Biochemical Sciences, 31(6), 342-348. https://doi.org/10.1016/J.TIBS.2006.04.003

Saxton, R. A., \& Sabatini, D. M. (2017). mTOR signaling in growth, metabolism, and disease. Cell, 168(6), 960-976. https://doi.org/10.1016/J. CELL.2017.02.004 
Schwenzer, H., Uhling, F. J., Chu, A., Pallett, L. J., Baumert, T. F., Maini, M., \& Fassati, A. (2019). Oxidative stress triggers selective tRNA retrograde transport in human cells during the integrated stress response. Cell Reports, 26, 3416-3428. https://doi.org/10.1016/j.celrep. 2019.02.077

Schaefer, M., Pollex, T., Hanna, K., Tuorto, F., Meusburger, M., Helm, M., \& Lyko, F. (2010). RNA methylation by Dnmt2 protects transfer RNAs against stress-induced cleavage. Genes \& Development, 24(15), 1590-1595. https://doi.org/10.1101/gad.586710

Schimmel, P. (2018). The emerging complexity of the tRNA world: Mammalian tRNAs beyond protein synthesis. Nature Reviews Molecular Cell Biology, 19(1), 45-58. https://doi.org/10.1038/nrm.2017.77

Sekine, Y., Zyryanova, A., Crespillo-Casado, A., Fischer, P. M., Harding, H. P., \& Ron, D. (2015). Mutations in a translation initiation factor identify target of a memory-enhancing compound. Science (New York, N.Y.), 348(6238), 1027-1030. https://doi.org/10.1126/SCIENCE. AAA6986

Sfakianos, A. P., Mellor, L. E., Pang, Y. F., Kritsiligkou, P., Needs, H., Abou-Hamdan, H., ... Whitmarsh, A. J. (2018). The mTOR-S6 kinase pathway promotes stress granule assembly. Cell Death \& Differentiation, 25(10), 1766-1780. https://doi.org/10.1038/s41418-018-0076-9

Sfakianos, A. P., Whitmarsh, A. J., \& Ashe, M. P. (2016). Ribonucleoprotein bodies are phased in. Retrieved from https://doi.org/10.1042/ BST20160117

Shahbazian, D., Roux, P. P., Mieulet, V., Cohen, M. S., Raught, B., Taunton, J., ... Sonenberg, N. (2006). The mTOR/PI3K and MAPK pathways converge on eIF4B to control its phosphorylation and activity. The EMBO Journal, 25(12), 2781-2791. https://doi.org/10.1038/sj. emboj. 7601166

Shaheen, H. H., \& Hopper, A. K. (2005). Retrograde movement of tRNAs from the cytoplasm to the nucleus in Saccharomyces cerevisiae. Proceedings of the National Academy of Sciences of the United States of America, 102(32), 11290-11295 https://doi.org/10.1073/pnas. 0503836102.

Shen, L., Gan, M., Tan, Z., Jiang, D., Jiang, Y., Li, M., ... Zhu, L. (2018). A novel class of tRNA-derived small non-coding RNAs respond to myocardial hypertrophy and contribute to intergenerational inheritance. Biomolecules, 8(3), 54. https://doi.org/10.3390/biom8030054

Shigematsu, M., Honda, S., Loher, P., Telonis, A. G., Rigoutsos, I., \& Kirino, Y. (2017). YAMAT-seq: An efficient method for high-throughput sequencing of mature transfer RNAs. Nucleic Acids Research, 45(9), gkx005. https://doi.org/10.1093/nar/gkx005

Shoulders, M. D., Ryno, L. M., Genereux, J. C., Moresco, J. J., Tu, P. G., Wu, C., ... Wiseman, R. L. (2013). Stress-independent activation of XBP1s and/or ATF6 reveals three functionally diverse ER Proteostasis environments. Cell Reports, 3(4), 1279-1292. https://doi.org/10. 1016/J.CELREP.2013.03.024

Sidrauski, C., Tsai, J. C., Kampmann, M., Hearn, B. R., Vedantham, P., Jaishankar, P., ... Walter, P. (2015). Pharmacological dimerization and activation of the exchange factor eIF2B antagonizes the integrated stress response. eLife, 4, e07314. https://doi.org/10.7554/eLife. 07314

Siekierka, J., Manne, V., \& Ochoa, S. (1984). Mechanism of translational control by partial phosphorylation of the alpha subunit of eukaryotic initiation factor 2. Proceedings of the National Academy of Sciences of the United States of America, 81(2), 352-356 https://doi. org/10.1073/pnas.81.2.352.

Sinvani, H., Haimov, O., Svitkin, Y., Sonenberg, N., Tamarkin-Ben-Harush, A., Viollet, B., \& Dikstein, R. (2015). Translational tolerance of mitochondrial genes to metabolic energy stress involves TISU and eIF1-eIF4GI cooperation in start codon selection. Cell Metabolism, 21 (3), 479-492. https://doi.org/10.1016/j.cmet.2015.02.010

Smith, A. M., Abu-Shumays, R., Akeson, M., \& Bernick, D. L. (2015). Capture, unfolding, and detection of individual tRNA molecules using a Nanopore device. Frontiers in Bioengineering and Biotechnology, 3, 91. https://doi.org/10.3389/fbioe.2015.00091

Sonenberg, N., \& Hinnebusch, A. G. (2009). Regulation of translation initiation in eukaryotes: Mechanisms and biological targets. Cell, 136 (4), 731-745. https://doi.org/10.1016/j.cell.2009.01.042

Spriggs, K. A., Bushell, M., Mitchell, S. A., \& Willis, A. E. (2005). Internal ribosome entry segment-mediated translation during apoptosis: The role of IRES-trans-acting factors. Cell Death \& Differentiation, 12(6), 585-591. https://doi.org/10.1038/sj.cdd.4401642

Spriggs, K. A., Bushell, M., \& Willis, A. E. (2010). Translational regulation of gene expression during conditions of cell stress. Molecular Cell, 40(2), 228-237. https://doi.org/10.1016/j.molcel.2010.09.028

Suragani, R. N. V. S., Zachariah, R. S., Velazquez, J. G., Liu, S., Sun, C.-W., Townes, T. M., \& Chen, J.-J. (2012). Heme-regulated eIF2 $\alpha$ kinase activated Atf4 signaling pathway in oxidative stress and erythropoiesis. Blood, 119(22), 5276-5284. https://doi.org/10.1182/blood-2011$10-388132$

Tam, A. B., Roberts, L. S., Chandra, V., Rivera, I. G., Nomura, D. K., Forbes, D. J., \& Niwa, M. (2018). The UPR activator ATF6 responds to Proteotoxic and Lipotoxic stress by distinct mechanisms. Developmental Cell, 46(3), 327-343.e7. https://doi.org/10.1016/J.DEVCEL.2018.04.023

Tameire, F., Verginadis, I. I., Leli, N. M., Polte, C., Conn, C. S., Ojha, R., ... Koumenis, C. (2019). ATF4 couples MYC-dependent translational activity to bioenergetic demands during tumour progression. Nature Cell Biology, 21(7), 889-899. https://doi.org/10.1038/s41556-019$0347-9$

Teske, B. F., Wek, S. A., Bunpo, P., Cundiff, J. K., McClintick, J. N., Anthony, T. G., \& Wek, R. C. (2011). The eIF2 kinase PERK and the integrated stress response facilitate activation of ATF6 during endoplasmic reticulum stress. Molecular Biology of the Cell, 22(22), $4390-4405$. https://doi.org/10.1091/mbc.E11-06-0510

Thompson, D. M., Lu, C., Green, P. J., \& Parker, R. (2008). tRNA cleavage is a conserved response to oxidative stress in eukaryotes. RNA (New York, N.Y.), 14(10), 2095-2103. https://doi.org/10.1261/rna.1232808

Torrent, M., Chalancon, G., de Groot, N. S., Wuster, A., \& Madan Babu, M. (2018). Cells alter their tRNA abundance to selectively regulate protein synthesis during stress conditions. Science Signaling, 11(546), eaat6409. https://doi.org/10.1126/scisignal.aat6409 
Trendel, J., Schwarzl, T., Horos, R., Prakash, A., Bateman, A., Hentze, M. W., \& Krijgsveld, J. (2019). The human RNA-binding proteome and its dynamics during translational arrest. Cell, 176(1-2), 391-403.e19. https://doi.org/10.1016/J.CELL.2018.11.004

Uniacke, J., Holterman, C. E., Lachance, G., Franovic, A., Jacob, M. D., Fabian, M. R., ... Lee, S. (2012). An oxygen-regulated switch in the protein synthesis machinery. Nature, 486(7401), 126-129. https://doi.org/10.1038/nature11055

Vattem, K. M., \& Wek, R. C. (2004). Reinitiation involving upstream ORFs regulates ATF4 mRNA translation in mammalian cells. Proceedings of the National Academy of Sciences of the United States of America, 101(31), 11269-11274 https://doi.org/10.1073/pnas.0400541101.

Vekich, J. A., Belmont, P. J., Thuerauf, D. J., \& Glembotski, C. C. (2012). Protein disulfide isomerase-associated 6 is an ATF6-inducible ER stress response protein that protects cardiac myocytes from ischemia/reperfusion-mediated cell death. Journal of Molecular and Cellular Cardiology, 53(2), 259-267. https://doi.org/10.1016/j.yjmcc.2012.05.005

Wang, M., Zhao, J., Zhang, L., Wei, F., Lian, Y., Wu, Y., ... Guo, C. (2017). Role of tumor microenvironment in tumorigenesis. Journal of Cancer, 8(5), 761-773. https://doi.org/10.7150/jca.17648

Wang, M., Law, M. E., Castellano, R. K., \& Law, B. K. (2018). The unfolded protein response as a target for anticancer therapeutics. Critical Reviews in Oncology/Hematology, 127, 66-79. https://doi.org/10.1016/J.CRITREVONC.2018.05.003

Wang, S., \& Kaufman, R. J. (2012). The impact of the unfolded protein response on human disease. The Journal of Cell Biology, 197(7), 857-867. https://doi.org/10.1083/jcb.201110131

Wek, S. A., Zhu, S., \& Wek, R. C. (1995). The histidyl-tRNA synthetase-related sequence in the eIF-2 alpha protein kinase GCN2 interacts with tRNA and is required for activation in response to starvation for different amino acids. Molecular and Cellular Biology, 15(8), 4497-4506. https://doi.org/10.1128/mcb.15.8.4497

Wu, D. C., Yao, J., Ho, K. S., Lambowitz, A. M., \& Wilke, C. O. (2018). Limitations of alignment-free tools in total RNA-seq quantification. BMC Genomics, 19(1), 510. https://doi.org/10.1186/s12864-018-4869-5

Yamasaki, S., Ivanov, P., Hu, G.-F., \& Anderson, P. (2009). Angiogenin cleaves tRNA and promotes stress-induced translational repression. The Journal of Cell Biology, 185(1), 35-42. https://doi.org/10.1083/jcb.200811106

Yamauchi, T., Masuda, T., Canver, M. C., Seiler, M., Semba, Y., Shboul, M., ... Maeda, T. (2018). Genome-wide CRISPR-Cas9 screen identifies leukemia-specific dependence on a pre-mRNA metabolic pathway regulated by DCPS. Cancer Cell, 33(3), 386-400.e5. https://doi.org/10. 1016/j.ccell.2018.01.012

Yoshida, H., Matsui, T., Yamamoto, A., Okada, T., \& Mori, K. (2001). XBP1 mRNA is induced by ATF6 and spliced by IRE1 in response to ER stress to produce a highly active transcription factor. Cell, 107(7), 881-891. https://doi.org/10.1016/S0092-8674(01)00611-0

Zeeshan, H. M. A., Lee, G. H., Kim, H.-R., \& Chae, H.-J. (2016). Endoplasmic reticulum stress and associated ROS. International Journal of Molecular Sciences, 17(3), 327. https://doi.org/10.3390/ijms17030327

Zheng, G., Qin, Y., Clark, W. C., Dai, Q., Yi, C., He, C., ... Pan, T. (2015). Efficient and quantitative high-throughput tRNA sequencing. Nature Methods, 12(9), 835-837. https://doi.org/10.1038/nmeth.3478

Zhu, M., Pan, Y., \& Dai, X. (2019). (p)ppGpp: The magic governor of bacterial growth economy, Current Genetics, 1-5. https://doi.org/10. 1007/s00294-019-00973-Z

\section{SUPPORTING INFORMATION}

Additional supporting information may be found online in the Supporting Information section at the end of this article.

How to cite this article: Pizzinga M, Harvey RF, Garland GD, et al. The cell stress response: extreme times call for post-transcriptional measures. WIREs RNA. 2019;e1578. https://doi.org/10.1002/wrna.1578 